\title{
Article \\ Diversity of Wood-Decaying Fungi in Wuliangshan Area, Yunnan Province, P.R. China
}

\author{
Xiao He ${ }^{1,2}$ and Chang-Lin Zhao ${ }^{1,2,3,4, *(D)}$ \\ 1 Key Laboratory for Forest Resources Conservation and Utilization in the Southwest Mountains of China, \\ Ministry of Education, Southwest Forestry University, Kunming 650224, China; fungixiaohe@163.com \\ 2 College of Biodiversity Conservation, Southwest Forestry University, Kunming 650224, China \\ 3 Yunnan Key Laboratory for Fungal Diversity and Green Development, Kunming Institute of Botany, \\ Chinese Academy of Sciences, Kunming 650201, China \\ 4 School of Life Sciences, Tsinghua University, Beijing 100084, China \\ * Correspondence: fungi@swfu.edu.cn
}

Citation: He, X.; Zhao, C.-L. Diversity of Wood-Decaying Fungi in Wuliangshan Area, Yunnan Province, P.R. China. Diversity 2022, 14, 131 https://doi.org/10.3390/d14020131 Academic Editors: Ipek Kurtboke and Michael Wink

Received: 28 January 2022

Accepted: 9 February 2022

Published: 11 February 2022

Publisher's Note: MDPI stays neutral with regard to jurisdictional claims in published maps and institutional affiliations.

Copyright: (C) 2022 by the authors. Licensee MDPI, Basel, Switzerland. This article is an open access article distributed under the terms and conditions of the Creative Commons Attribution (CC BY) license (https:// creativecommons.org/licenses/by/ $4.0 /)$.

\begin{abstract}
Five surveys were carried out in the Wuliangshan area, Yunnan Province, P.R. China, based on a combination of morphological features and molecular evidence. Around 2454 specimens of wooddecaying fungi were collected. The paper summarizes the obtained results on the wood-decaying fungi of this area, consisting in 95 species distributed in 59 genera, 23 families and 9 orders. Their hosts and substrates were also identified. A checklist of wood-decaying fungi is given. Sequences of the ITS nrRNA gene region of the studied specimens were generated and phylogenetic analysis was performed with maximum likelihood, maximum parsimony and Bayesian inference methods. The present list of wood-decaying fungi enriches the knowledge of fungal diversity worldwide and supplies the basic data for future applications.
\end{abstract}

Keywords: Basidiomycota; biological resources; diversity; mycota; Wuliangshan area

\section{Introduction}

Fungi are a diverse, monophyletic group of eukaryotes which have immense ecological and economic impacts. These organisms play an important role in ecosystems as diverse as soil, leaves, trees, wood, and hidden layers within their substrate [1]. Many fungi are microscopic or have cryptic life cycles that make detection difficult, and approximately 140 thousand species of fungi have been described, but the potential biodiversity of the group is likely to be in millions of species [2-4]. The diversity for flora of seed plants in the Yunnan Province is higher than other areas in China, and the endemic species of woody plants are rich, in which both supply good substrates for wood-decaying fungi. Wooddecaying fungi include most basidiomycetes and ascomycetes that grow on various kinds of wood, such as living trees, dead standing trees, fallen trunks, fallen branches and stumps, which can be used for industrial, medicinal, edible and economic value [5-10], and display a considerable ability to transform or degrade different environmental contaminants on their extensive organic compound degradation abilities [1].

The Wuliangshan area is located in the south-central part of the Yunnan Province, China, including the Wuliangshan National Nature Reserve and its surrounding areas, named for its location in the Wuliangshan Mountains. The geographical location is between $100^{\circ} 18^{\prime}-101^{\circ} 13^{\prime} \mathrm{E}$ and $23^{\circ} 12^{\prime}-24^{\circ} 55^{\prime} \mathrm{N}$ [11,12] with an altitude of $2000-3300 \mathrm{~m}$ and average annual precipitation more than $1500 \mathrm{~mm}$ [11,13]. The plant resources are rich in the Wuliangshan area, with 209 families, 1039 genera and 2574 species of seed plants [11,14]. The mid-mountain wet, semi-wet evergreen broad-leaved forest and monsoon evergreen broad-leaved forest are the main forest communities as the dominant species, which increase the fungal diversity of this area [11,12,15]. 
The wood-decaying fungi are mostly reported in northwest Yunnan Province, and few polypore and corticioid fungi have been reported there so far. According to the modern taxonomy, wood-decaying fungi mainly belong to ten orders of Agaricomycetes, viz., Agaricales, Auriculariales, Cantharellales, Corticiales, Gloeophyllales, Hymenochaetales, Polyporales, Russulales, Thelephorales and Trechisporales $[6,7,16]$. Therefore, the current wood-decaying fungi catalogues include poroid and corticioid hymenophores. In the present study, five field trips were carried out in the Wuliangshan area, and about 95 species which are distributed in 59 genera, 23 families, and 9 orders were identified from these materials. The aim of this work was to provide an updated checklist and mapping of wood-decaying fungi in the area, as well as to enrich the knowledge of the fungal diversity in this area.

\section{Materials and Methods}

\subsection{Sample Collection and Herbarium Specimen Preparation}

Fresh fruiting bodies of basidiomycetous macrofungi growing on angiosperm stumps, trunks and branches were collected by the systematically surveyed selected cells in the macroarea through the woods for 5 sampling points (approximately the four corners of the square and center) within $1 \times 1 \mathrm{~km}^{2} 2-3$ times every year in the Wuliangshan area of Yunnan Province from October 2017 to January 2019. The fruiting bodies require three basidiomata at least and each individual is up to $3 \mathrm{~cm}$ long, $2 \mathrm{~cm}$ wide, in which the smallest fruiting structure collected have to include the hymenophore. The samples were photographed in situ and their fresh macroscopic details were recorded. Photographs were recorded by a Jianeng 80D camera. All photos were focus stacked and merged using Helicon Focus software. Macroscopic details were recorded and transported to a field station where the fruit bodies were dried on an electronic food dryer (Fsfruit, Foshan, China) at $45{ }^{\circ} \mathrm{C}$ for $48 \mathrm{~h}$. Once dried, the specimens were sealed in envelope and Ziplock plastic bags and labeled. The dried specimens were deposited in the herbarium of Southwest Forestry University (SWFC), Kunming, Yunnan Province.

\subsection{Morphological Studies}

Macromorphological descriptions were based on field notes. Color terms are from Petersen [17]. Micromorphological data were obtained from the dried specimens and observed under a light microscope following Dai [6]. The following abbreviations were used for the micro characteristics descriptions: $\mathrm{KOH}=5 \%$ potassium hydroxide, $\mathrm{CB}=$ Cotton Blue, $\mathrm{CB}-=$ acyanophilous, $\mathrm{CB}+=$ cyanophilous, IKI = Melzer's reagent, IKI $-=$ both inamyloid and indextrinoid, $\mathrm{L}=$ mean spore length (arithmetic average of 30 spores), $\mathrm{W}=$ mean spore width (arithmetic average of 30 spores), $\mathrm{Q}=$ variation in the $\mathrm{L} / \mathrm{W}$ rationes between the specimens studied, $\mathrm{n}(\mathrm{a} / \mathrm{b})=$ number of spores (a) measured from given number (b) of specimens.

\subsection{Molecular Procedures and Phylogenetic Analysis}

CTAB rapid plant genome extraction kit-DN14 (Aidlab Biotechnologies Co., Ltd., Beijing, China) was used to obtain genomic DNA from dried specimens according to the manufacturer's instructions. ITS region was amplified with primer pair ITS5 and ITS4 [18]. The PCR procedure for ITS was as follows: initial denaturation at $95^{\circ} \mathrm{C}$ for $3 \mathrm{~min}$, followed by 35 cycles at $94{ }^{\circ} \mathrm{C}$ for $40 \mathrm{~s}, 58^{\circ} \mathrm{C}$ for $45 \mathrm{~s}$ and $72{ }^{\circ} \mathrm{C}$ for $1 \mathrm{~min}$, and a final extension of $72{ }^{\circ} \mathrm{C}$ for $10 \mathrm{~min}$. The PCR products were purified using a QIAquick PCR purification kit (Qiagen Inc., Valencia, CA, USA) and directly sequenced at Kunming Tsingke Biological Technology Limited Company, Kunming Yunnan Province, P.R. China. All newly generated sequences were deposited at GenBank (Table 1). 
Table 1. List of species, specimens, and GenBank accession numbers of sequences used in this study.

\begin{tabular}{|c|c|c|c|c|}
\hline \multirow{2}{*}{ Species Name } & \multirow{2}{*}{ Specimen No. } & GenBank Accession No. & \multirow{2}{*}{ References } & \multirow{2}{*}{ Country } \\
\hline & & ITS & & \\
\hline Abundisporus quercicola & CLZhao 10238 & MT159978 & Present study & China, Yunnan \\
\hline A. quercicola & Dai 3084 & KC415907 & [19] & China, Yunnan \\
\hline Agaricus campestris & MA Fungi 80998 & NR_151745 & Unpublished & USA, Bethesda \\
\hline Aleurodiscus botryosus & CBS 336.66 & MH858812 & {$[20]$} & Netherlands, Upsalalaan \\
\hline A. botryosus & CLZhao 4333 & MK343481 & Present study & China, Yunnan \\
\hline A. cerussatus & CLZhao 4715 & MK404310 & Present study & China, Yunnan \\
\hline A. cerussatus & SPG 3004 & MT831058 & [19] & Argentina, Esquel \\
\hline A. isabellinus & CLZhao 4405 & MK343482 & Present study & China, Yunnan \\
\hline A. isabellinus & He 5294 & MH109053 & [21] & China, Beijing \\
\hline A. mirabilis & CLZhao 4621 & MK343488 & Present study & China, Yunnan \\
\hline A. mirabilis & JMB 2152 & MT568513 & [19] & Argentina, Esquel \\
\hline A. subroseus & CLZhao 4722 & MK343489 & Present study & China, Yunnan \\
\hline A. subroseus & He 4814 & MH109055 & [21] & China, Beijing \\
\hline Antrodia malicola & CLZhao 3832 & MH114612 & Unpublished & China, Yunnan \\
\hline Athelia epiphylla & SFC 20180314-01 & MK992816 & [22] & Korea, Seoul \\
\hline Auricularia asiatica & CLZhao 3652 & MK268844 & Present study & China, Yunnan \\
\hline A. asiatica & OM 13932 & MZ618931 & [19] & China, Beijing \\
\hline A. cornea & CLZhao 4245 & MK343502 & Present study & China, Yunnan \\
\hline A. cornea & PDD 94825 & KX621146 & [23] & Thailand, Chiang Rai \\
\hline A. delicata & CLZhao 4403 & MK343505 & Present study & China, Yunnan \\
\hline A. delicata & MFLU162112 & KX621149 & [23] & Thailand, Chiang Rai \\
\hline A. mesenterica & BRNM 648573 & KP729279 & [24] & China, Beijing \\
\hline Bjerkandera adusta & CLZhao 4310 & MK343508 & Present study & China, Yunnan \\
\hline B. adusta & HHB-12826-Sp & KP134983 & [25] & USA, Worcester \\
\hline Boletus edulis & 375 & EU554664 & {$[26]$} & Spain, Cabrils \\
\hline Byssomerulius corium & CLZhao 9318 & MT177289 & Present study & China, Yunnan \\
\hline B. corium & FP-102382 & KP135007 & [25] & USA, Worcester \\
\hline Cantharellus cibarius & CL-67 & MK281467 & [27] & Canada, Prince George \\
\hline Ceriporia lacerata & CLZhao 3693 & MK268856 & Present study & China, Yunnan \\
\hline C. lacerata & FP-55521T & KP135024 & [25] & USA, Worcester \\
\hline Cerrena albocinnamomea & CLZhao 4193 & MK268860 & Present study & China, Yunnan \\
\hline C. albocinnamomea & Dai 12892 & KC485522 & [19] & China, Beijing \\
\hline C. zonata & CLZhao 3502 & MK268838 & Present study & China, Yunnan \\
\hline C. zonata & ICMP 16347 & MW862786 & [19] & New Zealand, Auckland \\
\hline Climacodon pulcherrimus & CBS 130.40 & MH856063 & [20] & Netherlands, Upsalalaan \\
\hline C. pulcherrimus & CLZhao 4379 & MK343524 & Present study & China, Yunnan \\
\hline Corticium roseocarneum & CBS 330.66 & MH858810 & [20] & Netherlands, Upsalalaan \\
\hline C. roseocarneum & CLZhao 3562 & MK268877 & Present study & China, Yunnan \\
\hline C. roseum & CBS 104.52 & MH856944 & [20] & Netherlands, Upsalalaan \\
\hline Crustodontia chrysocreas & CLZhao 4143 & MK269228 & Present study & China, Yunnan \\
\hline C. chrysocreas & KMRB 18041009 & MK120528 & [19] & Korea, Seoul \\
\hline Dacrymyces cyrtosporus & PDD 107980 & NR_148190 & [28] & USA, Bethesda \\
\hline D. flabelliformis & PDD 76696 & NR_166790 & [29] & USA, Bethesda \\
\hline D. stillatus & UPS F-939814 & MN595677 & [30] & Sweden, Uppsala \\
\hline Daedaleopsis confragosa & CLZhao 4260 & MK343522 & Present study & China, Yunnan \\
\hline D. confragosa & Cui 2883 & KU900526 & [19] & China, Beijing \\
\hline Datronia mollis & CLZhao 4429 & MK343523 & Present study & China, Yunnan \\
\hline D. mollis & KUC 20121123-22 & KJ668554 & [19] & Korea, Seoul \\
\hline D. stereoides & CLZhao 9937 & MT193539 & Present study & China, Yunnan \\
\hline D. stereoides & Cui 8132 & JX559270 & [19] & China, Beijing \\
\hline Earliella scabrosa & CLZhao 3722 & MK268896 & Present study & China, Yunnan \\
\hline E. scabrosa & Cui 6236 & КС867366 & [19] & China, Beijing \\
\hline Fibroporia albicans & CLZhao 4416 & MK343526 & Present study & China, Yunnan \\
\hline F. albicans & Dai 10595 & NR_153980 & [31] & China, Beijing \\
\hline Flavodon ambrosius & CLZhao 3341 & MḦ114652 & Present study & China, Yunnan \\
\hline F. ambrosius & Hulcr 12546 & LC216231 & [32] & USA, Gainesville \\
\hline Fomes fomentarius & CLZhao 4393 & MK343528 & Present study & China, Yunnan \\
\hline F. fomentarius & Cui 8020 & JX290073 & [19] & China, Beijing \\
\hline Ganoderma australe & CLZhao 4351 & MK343538 & Present study & China, Yunnan \\
\hline G. australe & HMAS 86595 & AY884184 & [19] & China, Beijing \\
\hline Geastrum pectinatum & MJ 9030 & KC581962 & [33] & Sweden, Goteborg \\
\hline Gloeodontia yunnanensis & CLZhao 10504 & MN908252 & Present study & China, Yunnan \\
\hline G. yunnanensis & CLZhao 11058 & MN908253 & Present study & China, Yunnan \\
\hline
\end{tabular}


Table 1. Cont.

\begin{tabular}{|c|c|c|c|c|}
\hline \multirow{2}{*}{ Species Name } & \multirow{2}{*}{ Specimen No. } & \multirow{2}{*}{$\begin{array}{c}\text { GenBank Accession No. } \\
\text { ITS }\end{array}$} & \multirow{2}{*}{ References } & \multirow{2}{*}{ Country } \\
\hline & & & & \\
\hline Gloeophyllum sepiarium & CBS 293.51 & MH856865 & {$[20]$} & Netherlands, Upsalalaan \\
\hline G. sepiarium & CLZhao 3473 & MK268934 & Present study & China, Yunnan \\
\hline Gomphus clavatus & EL 64/03 & EU118628 & [34] & Sweden, Goteborg \\
\hline Heterobasidion insulare & CLZhao 4071 & MK268945 & Present study & China, Yunnan \\
\hline H. insulare & Dai 13933 & MT146489 & [35] & China, Beijing \\
\hline Hexagonia glabra & CLZhao 3589 & MK268955 & Present study & China, Yunnan \\
\hline H. glabra & Cui 16796 & MK192431 & [36] & China, Beijing \\
\hline H. tenuis & CLZhao 3485 & MK268956 & Present study & China, Yunnan \\
\hline H. tenuis & Cui 8468 & JX559277 & [37] & China, Beijing \\
\hline Hymenochaete innexa & CLZhao 4433 & MK343546 & Present study & China, Yunnan \\
\hline H. innexa & OUT 855 & MT596387 & [19] & Italy, Torino \\
\hline H. xerantica & CLZhao 2789 & MK343628 & Unpublished & China, Yunnan \\
\hline Hyphoderma moniliforme & CLZhao 10176 & MT246965 & Present study & China, Yunnan \\
\hline H. moniliforme & Wu 0211-46 & КС928284 & [38] & China, Taiwan \\
\hline H. mutatum & CBS 291.36 & MH855803 & [20] & Netherlands, Upsalalaan \\
\hline H. mutatum & CLZhao 10019 & MT246969 & Present study & China, Yunnan \\
\hline H. nudicephalum & CBS 125855 & MH863811 & [20] & Netherlands, Upsalalaan \\
\hline H. nudicephalum & CLZhao 3481 & MK269020 & Present study & China, Yunnan \\
\hline H. transiens & CLZhao 9628 & MT246975 & Present study & China, Yunnan \\
\hline H. transiens & NH 12304 & DQ677504 & [39] & Sweden, Goteborg \\
\hline Hysterangium atlanticum & Fungos 2115 & NR_165211 & [40] & Slovenia, Ljubljana \\
\hline Irpex lacteus & CLZhao 4338 & MK343588 & Present study & China, Yunnan \\
\hline I. lacteus & FD-9 & KP135026 & [25] & USA, Worcester \\
\hline Junghuhnia crustacea & CLZhao 3588 & MK269088 & Present study & China, Yunnan \\
\hline J. crustacea & X 1127 & JN710554 & [41] & Finland, Helsinki \\
\hline J. nitida & CLZhao 3474 & MK269086 & Present study & China, Yunnan \\
\hline J. nitida & KHL 11903 & EU118638 & [34] & Sweden, Goteborg \\
\hline Laxitextum incrustatum & CLZhao 9273 & MT159974 & Present study & China, Yunnan \\
\hline L. incrustatum & STMA 14285 & KT722621 & [42] & Germany, Braunschweig \\
\hline Lenzites betulinus & CLZhao 10151 & MT193546 & Present study & China, Yunnan \\
\hline L. betulinus & Cui 7095 & JX290075 & [19] & China, Beijing \\
\hline Lopharia mirabilis & CLZhao 3518 & MK269105 & Present study & China, Yunnan \\
\hline L. mirabilis & Dai 13722 & MF626346 & [43] & China, Beijing \\
\hline Lyomyces bambusinus & CLZhao 3675 & MN945969 & Present study & China, Yunnan \\
\hline L. bambusinus & CLZhao 4840 & MN945971 & Present study & China, Yunnan \\
\hline L.cremeus & CLZhao 4138 & MN945974 & Present study & China, Yunnan \\
\hline L. cremeus & CLZhao 8295 & MN945972 & Present study & China, Yunnan \\
\hline L. macrosporus & CLZhao 4516 & MN945977 & Present study & China, Yunnan \\
\hline L. macrosporus & CLZhao 8605 & MN945975 & Present study & China, Yunnan \\
\hline L. wuliangshanensis & CLZhao 4475 & MN945983 & Present study & China, Yunnan \\
\hline L. wuliangshanensisd & CLZhao 4108 & MN945980 & Present study & China, Yunnan \\
\hline Megasporia ellipsoidea & CLZhao 10360 & MT193554 & Present study & China, Yunnan \\
\hline M. ellipsoidea & Cui 5222 & JQ314367 & [19] & China, Beijing \\
\hline M. major & CLZhao 10363 & MT193555 & Present study & China, Yunnan \\
\hline M. major & Yuan 1183 & JQ314365 & [19] & China, Beijing \\
\hline $\begin{array}{l}\text { Megasporoporiella } \\
\text { pseudocavernulosa }\end{array}$ & CLZhao 9339 & MK894044 & Present study & China, Yunnan \\
\hline M. pseudocavernulosa & Cui 11106 & KX900657 & [19] & China, Beijing \\
\hline M. subcavernulosa & CLZhao 4442 & MK343599 & Present study & China, Yunnan \\
\hline M. subcavernulosa & Cui 10050 & JQ314357 & [19] & China, Beijing \\
\hline Microporus vernicipes & CLZhao 3672 & MK269132 & Present study & China, Yunnan \\
\hline M. vernicipes & Dai 7252 & KX880619 & [19] & China, Beijing \\
\hline M. xanthopus & CLZhao 4280 & MT159985 & Present study & China, Yunnan \\
\hline M. xanthopus & Dai 12076 & KX880620 & [19] & China, Beijing \\
\hline Neodatronia sinensis & CLZhao 9471 & MT193563 & Present study & China, Yunnan \\
\hline N. sinensis & Cui 9949 & KX900663 & [19] & China, Beijing \\
\hline Oxychaete cervinogilva & CLZhao 3462 & MK269143 & Present study & China, Yunnan \\
\hline O. cervinogilva & Schigel 5216 & KX752596 & [44] & Finland, Helsinki \\
\hline Peniophora cinerea & 0911 TES27A5 & LN808982 & [19] & Spain, Sevilla \\
\hline P. cinerea & CLZhao 9254 & MT159975 & Present study & China, Yunnan \\
\hline P. incarnata & CBS 430.72 & MH860518 & [20] & Netherlands, Upsalalaan \\
\hline P. incarnata & CLZhao 9859 & MT159976 & Present study & China, Yunnan \\
\hline P. pesudoversicolor & CLZhao 9415 & MT159977 & Present study & China, Yunnan \\
\hline P. pseudoversicolor & CBS 338.66 & MH858814 & [20] & Netherlands, Upsalalaan \\
\hline Peniophorella fissurata & CLZhao 11412 & MN864261 & Present study & China, Yunnan \\
\hline P. fissurata & CLZhao 4539 & MN864259 & Present study & China, Yunnan \\
\hline P. pubera & CLZhao 9336 & MK894055 & Present study & China, Yunnan \\
\hline
\end{tabular}


Table 1. Cont.

\begin{tabular}{|c|c|c|c|c|}
\hline \multirow{2}{*}{ Species Name } & \multirow{2}{*}{ Specimen No. } & \multirow{2}{*}{$\begin{array}{c}\text { GenBank Accession No. } \\
\text { ITS }\end{array}$} & \multirow{2}{*}{ References } & \multirow{2}{*}{ Country } \\
\hline & & & & \\
\hline P. pubera & NH 10380 & DQ647504 & {$[45]$} & Sweden, Goteborg \\
\hline P. rude & CLZhao 3360 & MH114830 & Present study & China, Yunnan \\
\hline P. rude & Wu 9307-39 & DQ647499 & [45] & Sweden, Goteborg \\
\hline Perenniporia luteola & CLZhao 10334 & MT193564 & Present study & China, Yunnan \\
\hline P. luteola & Dai 13094 & KX900679 & [19] & China, Beijing \\
\hline P. mopanshanensis & CLZhao 4677 & MK404422 & Present study & China, Yunnan \\
\hline P. mopanshanensis & CLZhao 5145 & MH784912 & Present study & China, Yunnan \\
\hline $\begin{array}{l}\text { Phaeophlebiopsis } \\
\text { peniophoroides }\end{array}$ & CLZhao 3637 & MK269159 & Present study & China, Yunnan \\
\hline P. peniophoroides & FP-150577 & KP135417 & [25] & USA, Worcester \\
\hline Phallus impudicus & KHTW 08001 & MG678529 & [46] & Brazil, Manaus \\
\hline $\begin{array}{c}\text { Phanerochaete } \\
\text { angustocystidiata }\end{array}$ & CLZhao 9280 & MT177305 & Present study & China, Yunnan \\
\hline P. angustocystidiata & KUC20121102-15 & KJ668492 & [19] & Korea, Seoul \\
\hline P. australis & CLZhao 3571 & MK269240 & Present study & China, Yunnan \\
\hline P. australis & HHB-7105-Sp & KP135081 & [25] & USA, Worcester \\
\hline P. concrescens & CLZhao 4367 & MK404430 & Present study & China, Yunnan \\
\hline P. concrescens & Spirin 6111 & KP994352 & [47] & Russia, Saint-Petersburg \\
\hline P. sanguineocarnosa & CLZhao 4447 & MK343613 & Present study & China, Yunnan \\
\hline P. sanguineocarnosa & HHB-2189 & KP135124 & [25] & USA, Worcester \\
\hline P. sordida & CLZhao 3407 & MK269174 & Present study & China, Yunnan \\
\hline P. sordida & FD-241 & KP135136 & [25] & USA, Worcester \\
\hline Phlebiopsis castanea & CLZhao 3501 & MK269230 & Present study & China, Yunnan \\
\hline P. castanea & Spirin 5295 & KX752610 & [44] & Finland, Helsinki \\
\hline P. crassa & CLZhao 3339 & MT177325 & Present study & China, Yunnan \\
\hline P. crassa & KKN-86 & KP135394 & [25] & USA, Worcester \\
\hline $\begin{array}{c}\text { Rhomboidia } \\
\text { wuliangshanensis }\end{array}$ & CLZhao 4406 & MK860715 & Present study & China, Yunnan \\
\hline R. wuliangshanensis & CLZhao 4411 & MK860716 & Present study & China, Yunnan \\
\hline Rigidoporus pouzarii & CLZhao 4524 & MK404499 & Present study & China, Yunnan \\
\hline R. pouzarii & MJ 123_93 & JQ409464 & [19] & $\begin{array}{c}\text { Czech Republic, South } \\
\text { Bohemia }\end{array}$ \\
\hline Russula recondita & LUG 19058 & NR_147635 & [48] & USA, Bethesda \\
\hline Sebacina incrustans & JMP 0084 & EU819442 & [49] & USA, Wisconsin \\
\hline Serpula dendrocalami & CLZhao 3136 & MK863399 & Present study & China, Yunnan \\
\hline S. dendrocalami & CLZhao 3607 & MK863404 & Present study & China, Yunnan \\
\hline Sistotrema brinkmannii & ATCC 36164 & DQ899095 & [19] & USA, Stillwater \\
\hline S. brinkmannii & CLZhao 9324 & MT159987 & Present study & China, Yunnan \\
\hline $\begin{array}{c}\text { Sistotremastrum } \\
\text { guttuliferum }\end{array}$ & BHI-F755a & MW488061 & [19] & USA, West Lafayette \\
\hline S. guttuliferum & CLZhao 9771 & MT159990 & Present study & China, Yunnan \\
\hline Steccherinum bourdotii & CLZhao 4297 & MK343648 & Present study & China, Yunnan \\
\hline S. bourdotii & U 107 & MN749593 & {$[50]$} & Arabia, Hail \\
\hline S. ochraceum & CLZhao 4154 & MK404504 & Present study & China, Yunnan \\
\hline S. ochraceum & LE-BIN 3984 & MK795064 & [19] & Russia, Saint Petersburg \\
\hline Terana coerulea & CLZhao 9803 & MT177329 & Present study & China, Yunnan \\
\hline T. coerulea & FP-104073 & KP134980 & [25] & USA, Worcester \\
\hline Thelephora terrestris & JMP 0086 & EU819444 & [49] & USA, La Crosse \\
\hline Tinctoporellus epimiltinus & CLZhao 3605 & MK269225 & Present study & China, Yunnan \\
\hline T. epimiltinus & PR1147 & KY948721 & {$[51]$} & USA, Massachusetts \\
\hline Trametes ellipsosopia & CLZhao 3774 & MK269226 & Present study & China, Yunnan \\
\hline T. ellipsospora & Cui 6259 & JN048767 & [52] & China, Beijing \\
\hline T. hirsuta & CLZhao 3572 & MK269220 & Present study & China, Yunnan \\
\hline T. hirsuta & TH 158 & MF960866 & [53] & Czech Republic, Brno \\
\hline T. pavonia & CLZhao 3740 & MK269222 & Present study & China, Yunnan \\
\hline T. pavonia & PR2178 & JN164959 & [54] & USA, Worcester \\
\hline T. versicolor & CLZhao 4170 & MK269115 & Present study & China, Yunnan \\
\hline T. versicolor & F-1599 & MN749366 & [19] & USA, West Lafayette \\
\hline Trametopsis cervina & CLZhao 9449 & MW418032 & Present study & China, Yunnan \\
\hline T. cervina & TJV 93_216T & JN165020 & [54] & USA, Worcester \\
\hline Trechispora echinospora & MA-Fungi 82485 & JX392847 & {$[55]$} & Spain, Madrid \\
\hline T. nivea & A 1683 & MT458536 & [19] & Greece, Athens \\
\hline T. nivea & CLZhao 10154 & MT159996 & Present study & China, Yunnan \\
\hline Truncospora ochroleuca & CLZhao 4350 & MK343685 & Present study & China, Yunnan \\
\hline T. ochroleuca & BCC 16648 & KР059107 & [19] & Thailand, Khlong \\
\hline
\end{tabular}


Sequencher 4.6 (GeneCodes, Ann Arbor, MI, USA) was used to edit the DNA sequence. Sequences were aligned in MAFFT 7 (http://mafft.cbrc.jp/alignment/server/, accessed on 15 November 2021) using the "G-INS-i" strategy and manually adjusted in BioEdit [56]. Sequence of Dacrymyces from type species as D. stillatus Nees obtained from GenBank was used as an outgroup to root tree following James et al. [1] in ITS analysis (Figure 1). Sequences from type materials of Dacrymyces flabelliformis Burds. and Laursen and D. cyrtosporus Shirouzu acquired from GenBank were utilized as another outgroup to root tree following James et al. [1] in ITS analysis (Figure 2).

Maximum parsimony analysis was applied to the ITS dataset sequences. Approaches to phylogenetic analysis followed Zhao and $\mathrm{Wu}$ [57] and the tree construction procedure was performed in PAUP* version 4.0b10 [58]. All characters were equally weighted and gaps were treated as missing data. Trees were inferred using the heuristic search option with TBR branch swapping and 1000 random sequence additions. Max-trees were set to 5000, branches of zero length were collapsed and all parsimonious trees were saved. Clade robustness was assessed using a bootstrap (BT) analysis with 1000 replicates [59]. Descriptive tree statistics tree length (TL), consistency index (CI), retention index (RI), rescaled consistency index $(\mathrm{RC})$, and homoplasy index $(\mathrm{HI})$ were calculated for each Maximum Parsimonious Tree (MPT) generated. Sequences were also analyzed using maximum likelihood (ML) with RAxML-HPC2 through the Cipres Science Gateway [60]. Branch support (BS) for ML analysis was determined by 1000 bootstrap replicates.

MrModeltest 2.3 [61] was used to determine the best-fit evolution model for each data set for Bayesian inference (BI). Bayesian inference was calculated with MrBayes3.1.2 with a general time reversible $(\mathrm{GTR}+\mathrm{I}+\mathrm{G})$ model of DNA substitution and a gamma distribution rate variation across sites [62]. Four Markov chains were run for 2 runs from random starting trees for 760 thousand generations (Figure 1) and 6.4 million generations (Figure 2), and trees were sampled every 100 generations. The first one-fourth generations were discarded as burn-in. A majority rule consensus tree of all remaining trees was calculated. Branches were considered as significantly supported if they received maximum likelihood bootstrap (BS) $>70 \%$, maximum parsimony bootstrap (BT) $>50 \%$, or Bayesian posterior probabilities $(\mathrm{BPP})>0.95$.

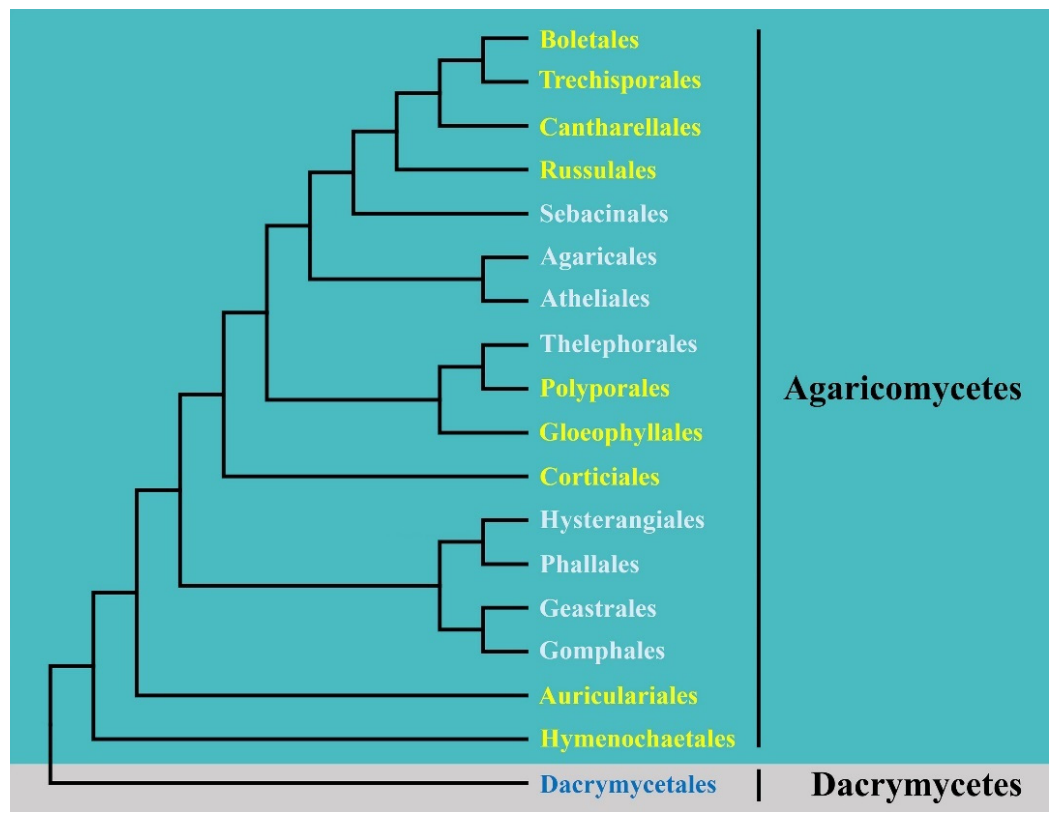

Figure 1. Maximum parsimony strict consensus tree illustrating the phylogeny of 9 orders in Agaricomycetes based on ITS sequences. Branches are labeled with maximum likelihood bootstrap $>70 \%$, parsimony bootstrap $>50 \%$ and Bayesian posterior probabilities $>0.97$, respectively. The 9 orders conducted in present studies are labeled in light yellow. 


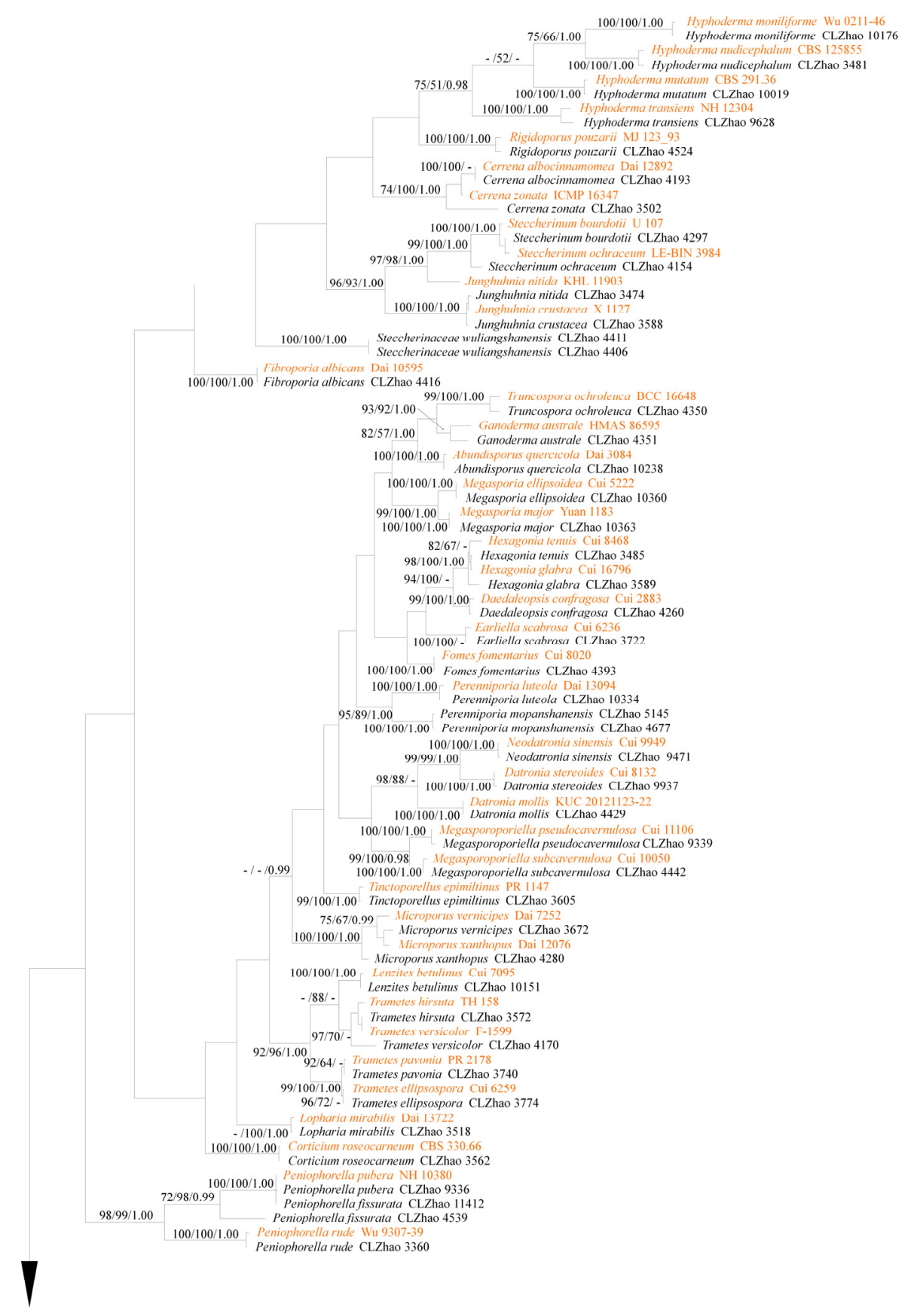

Figure 2. Cont. 


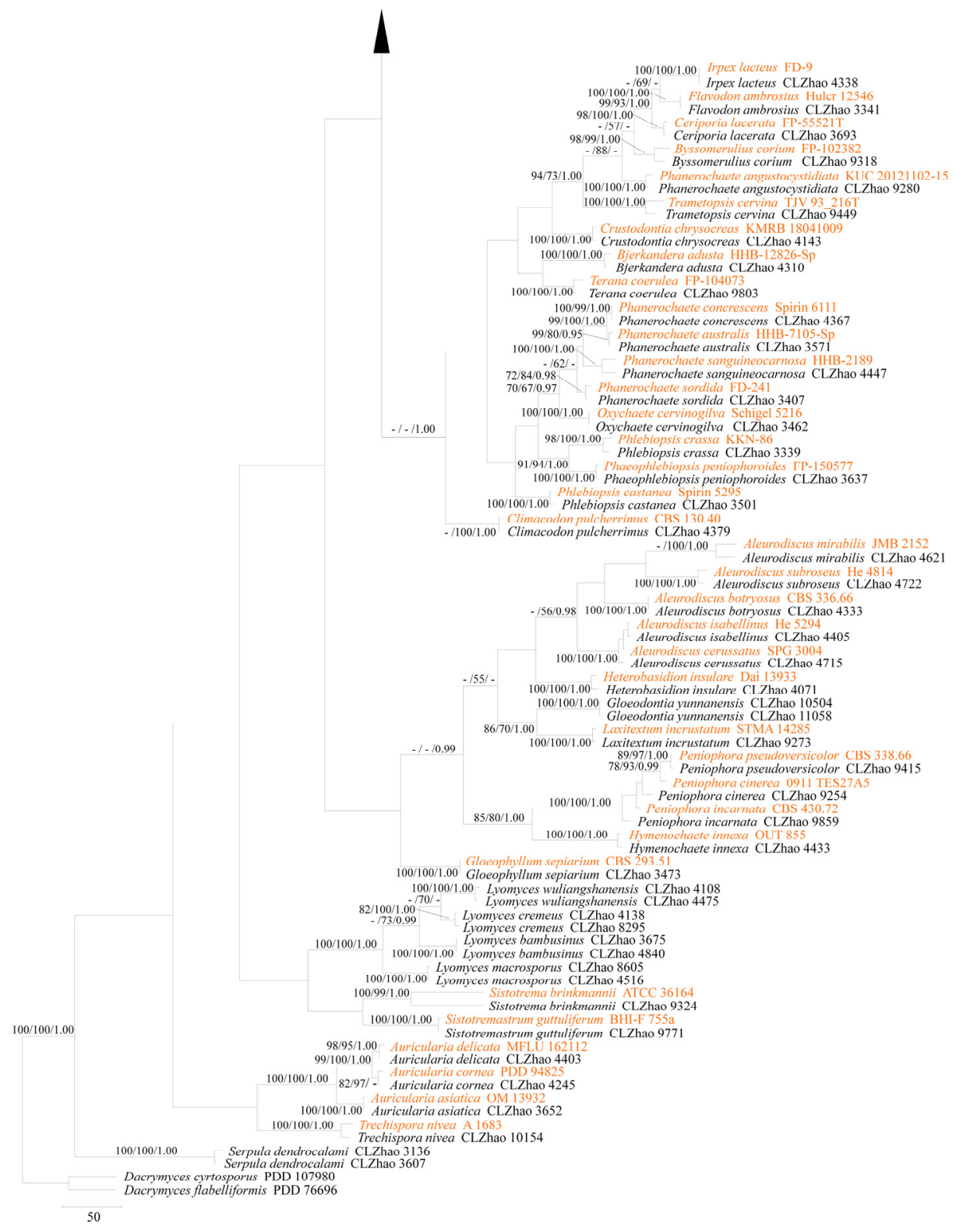

Figure 2. Maximum parsimony strict consensus tree illustrating the phylogeny of 85 species in Agaricomycetes based on ITS sequences. Branches are labeled with maximum likelihood bootstrap $>70 \%$, parsimony bootstrap $>50 \%$ and Bayesian posterior probabilities $>0.97$, respectively. The sequences of collections labeled in orange are downloaded from GenBank, while those in black are generated in this study.

\section{Results}

\subsection{Molecular Phylogeny}

The ITS dataset (Figure 1) included sequences from 18 fungal specimens representing 18 species. The dataset had an aligned length of 1017 characters, of which 326 characters were constant, 272 parsimony-uninformative, and 419 parsimony-informative. Maximum parsimony analysis yielded three equally parsimonious trees $(\mathrm{TL}=2801, \mathrm{CI}=0.4763$, $\mathrm{HI}=0.5237, \mathrm{RI}=0.0259, \mathrm{RC}=0.0123)$. The best-fit model for ITS alignment estimated and applied in the Bayesian method was $\mathrm{GTR}+\mathrm{I}+\mathrm{G}$, lset nst =6, rates = invgamma; prset statefreqpr $=$ dirichlet $(1,1,1,1)$. The Bayesian method resulted in a similar topology with an average standard deviation of split frequencies $=0.009891(\mathrm{BI})$. 
The phylogeny (Figure 1) inferred from ITS sequences demonstrated that ninetyfive species nested in nine orders, including Auriculariales, Boletales, Cantharellales, Corticiales, Gloeophyllales, Hymenochaetales, Polyporales, Russulales and Trechisporales of Agaricomycetes.

The ITS dataset (Figure 2) included sequences from 172 fungal specimens representing 87 species. The dataset had an aligned length of 1107 characters, of which 351 characters were constant, 52 parsimony-uninformative, and 704 parsimony-informative. Maximum parsimony analysis yielded 10 equally parsimonious trees $(\mathrm{TL}=7174, \mathrm{CI}=0.2319$, $\mathrm{HI}=0.7681, \mathrm{RI}=0.6952, \mathrm{RC}=0.1613)$. The best-fit model for ITS alignment estimated and applied in the Bayesian method was GTR $+\mathrm{I}+\mathrm{G}$, lset nst = 6, rates = invgamma; prset statefreqpr $=$ dirichlet $(1,1,1,1)$. The Bayesian method resulted in a similar topology with an average standard deviation of split frequencies $=0.012495(\mathrm{BI})$, and the effective sample size (ESS) across the two runs is the double of the average ESS (avg ESS) $=223.5$.

The phylogeny (Figure 2) inferred from ITS sequences demonstrated that 2454 specimens of wood-decaying fungi belonged to 85 taxa and all of them nested into class Agaricomycetes.

\subsection{Checklist}

An alphabetical list (according to genus name) of wood-decaying fungi identified in these investigations is given below. The authors of scientific names are according to the second edition of Authors of Fungal Names (http:/ / www.indexfungorum.org/AuthorsO fFungalNames.htm, accessed on 15 November 2021). Substrate and collecting data are provided after the name of each species. The hosts are listed alphabetically, and within the same host tree, they are arranged by the following order: living tree, dead standing tree, trunk, fallen branch and stump. The collectors and collection numbers are listed alphabetically as well $[6,63]$.

Abundisporus quercicola Y.C. Dai, in Dai, Niemelä and Kinnunen, Ann. bot. fenn. 39(3): 171 (2002).

Specimens examined: on dead tree of angiosperm, 9 January 2019, CLZhao 10238; on the trunk of angiosperm, 10 January 2019, CLZhao 10,381 (SWFC).

Distribution: Asia-China [64].

Aleurodiscus botryosus Burt, Ann. Mo. bot. Gdn 5: 198 (1918).

Specimens examined: on the fallen angiosperm branch, 5 October 2017, CLZhao 4333 (SWFC).

Distribution: Asia-China; Europe-France Portugal, Spain the United Kingdom; North America-Canada the United States; Oceania-Australia, New Zealand [64].

Aleurodiscus cerussatus (Bres.) Höhn. and Litsch., Sber. Akad. Wiss. Wien, Math.naturw. Kl., Abt. 1 116: 808 (1907).

Specimens examined: on the fallen branch of angiosperm, 6 October 2017, CLZhao 4715 (SWFC).

Distribution: Asia_China; Europe—Denmark, Estonia, Italy, Norway, Russia, Spain, Sweden; North America - the United States; South America-Argentina; Oceania-Australia [64].

Aleurodiscus isabellinus S.H. He and Y.C. Dai, in Tian, Ghobad-Nejhad, He and Dai, MycoKeys 37: 100 (2018).

Specimens examined: on the trunk of angiosperm, 5 October 2017, CLZhao 4102; 6 October 2017, CLZhao 4405, CLZhao 4600; 4 January 2019, CLZhao 9300; on the fallen branch of angiosperm, 5 October 2017, CLZhao 4369, CLZhao 4435, CLZhao 4510, CLZhao 4564, CLZhao 4718; 4 January 2019, CLZhao 9284, CLZhao 9359, CLZhao 9364, CLZhao 9615, CLZhao 9643; 7 January 2019, CLZhao 9781, CLZhao 9861; 9 January 2019, CLZhao 10,095 (SWFC).

Distribution: Asia-China [64].

Aleurodiscus mirabilis (Berk. and M.A. Curtis) Höhn., Sber. Akad. Wiss. Wien, Math.-naturw. K1., Abt. 1 118: 818 (1909).

Specimens examined: on the fallen branch of angiosperm, 6 October 2017, CLZhao 4621 (SWFC). 
Distribution: Africa-Gabon, Mauritius, Tanzania; Asia-China, Japan, Sri Lanka; North America-Cuba, Jamaica, the United States; South America-Brazil, Colombia, Ecuador, Venezuela; Oceania-Australia, New Zealand [64].

Aleurodiscus subroseus S.H. He and Y.C. Dai, in Tian, Ghobad-Nejhad, He and Dai, MycoKeys 37: 102 (2018).

Specimens examined: on the fallen branch of angiosperm, 6 October 2017, CLZhao 4722 (SWFC).

Distribution: Asia-China [64].

Asterostroma muscicola (Berk. and M.A. Curtis) Massee, J. Linn. Soc., Bot. 25(no. 170): 155 (1889).

Specimens examined: on the trunk of angiosperm, 2 October 2017, CLZhao 3577 (SWFC).

Distribution: Africa-Malawi, Rwanda, Tanzania; Asia-China, India, Indonesia; North America-Bahamas, Cuba, Canada, Jamaica, Mexico, the United States; South America-Brazil, Colombia, Venezuela; Oceania-Australia [64].

Auricularia asiatica Bandara and K.D. Hyde, in Bandara, Karunarathna, Phillips, Mortimer, Xu, Kakumyan and Hyde, Phytotaxa 292(1): 24 (2016).

Specimens examined: on the trunk of angiosperm, 2 October 2017, CLZhao 3652 (SWFC).

Distribution: Asia-China, Thailand [64].

Auricularia cornea Ehrenb., in Nees von Esenbeck (Ed.), Horae Phys. Berol.: 91 (1820).

Specimens examined: on the dead tree of angiosperm, 9 January 2019, CLZhao 10129; on the trunk of angiosperm, 5 October 2017, CLZhao 4245, CLZhao 4282, CLZhao 4306, CLZhao 4483; 4 January 2019, CLZhao 9272, CLZhao 9330; 9 January 2019, CLZhao 10009, CLZhao 10,324 (SWFC).

Distribution: Africa-South Africa, Tanzania; Asia-China, Indonesia; North AmericaMexico, the United States; South America-Brazil [64].

Auricularia delicata (Mont. ex Fr.) Henn., Bot. Jb. 17: 492 (1893).

Specimens examined: on the trunk of angiosperm, 6 October 2017, CLZhao 4403, CLZhao 4582 (SWFC).

Distribution: Asia-China, India; North America-Mexico, the United States [64].

Bjerkandera adusta (Willd.) P. Karst., Meddn Soc. Fauna Flora fenn. 5: 38 (1879).

Specimens examined: on the fallen branch of angiosperm, 5 October 2017, CLZhao 4310; 6 October 2017, CLZhao 4371, CLZhao 4374, CLZhao 4376, CLZhao 4427, CLZhao 4444, CLZhao 4546, CLZhao 4625, CLZhao 4637; 7 January 2019, CLZhao 9844; 4 January 2019, CLZhao 9345; 5 January 2019, CLZhao 9508; 10 January 2019, CLZhao 10385, CLZhao 10,404 (SWFC).

Distribution: Asia-China, India, Japan, Pakistan, Thailand, Vietnam; Europe-Bulgaria, Finland, Germany, Italy, Norway, Poland, Russia, Spain, Sweden, the United Kingdom, Ukraine; North America-Canada, the United States [64].

Byssomerulius corium (Pers.) Parmasto, Eesti NSV Tead. Akad. Toim., Biol. seer 16(4): 383 (1967).

Specimens examined: on the trunk of angiosperm, 4 January 2019, CLZhao 9318; on the fallen branch of angiosperm, 4 January 2019, CLZhao 9390, CLZhao 10,110 (SWFC).

Distribution: Asia-China, Turkey; Europe-Belgium, Croatia, Estonia, Finland, France, Germany, Greece, Ireland, Italy, Norway, Poland, Portugal, Romania, Serbia, Spain, Sweden, Switzerland, the United Kingdom, Ukraine [64].

Ceriporia lacerata N. Maek., Suhara and R. Kondo, in Suhara, Maekawa, Kaneko, Hattori, Sakai and Kondo, Mycotaxon 86: 342 (2003).

Specimens examined: on the trunk of angiosperm, 3 October 2017, CLZhao 3693 (SWFC).

Distribution: Asia-China, Japan; Europe-Finland; North America-the United States [64].

Cerrena albocinnamomea (Y.C. Dai and Niemelä) H.S. Yuan, Mycol. Progr. 13(2): 362 (2013).

Specimens examined: on the fallen branch of Alnus nepalensis, 4 January 2019, CLZhao 9281; on the trunk of angiosperm, 5 October 2017, CLZhao 4197; 4 January 2019, CLZhao 9270, CLZhao 9342; on the fallen branch of angiosperm, 5 October 2017, CLZhao 4193 (SWFC). 
Distribution: Asia-China, India, Japan, South Korea [64].

Cerrena zonata (Berk.) H.S. Yuan, Mycol. Progr. 13(2): 363 (2013).

Specimens examined: on the trunk of angiosperm, 2 October 2017, CLZhao 3581; 5 October 2017, CLZhao 4178; 6 January 2019, CLZhao 9633, CLZhao 9641; on the fallen branch of angiosperm, 2 October 2017, CLZhao 3502 (SWFC).

Distribution: Asia-China, India, Japan, Thailand, Vietnam; Europe-Russia; South America-Argentina; Oceania-Australia, New Zealand [64].

Climacodon pulcherrimus (Berk. and M.A. Curtis) Nikol., Flora Plantarum Cryptogamarum URSS 6, Fungi 6(Fungi, 2): 194 (1961).

Specimens examined: on the trunk of angiosperm, 6 October 2017, CLZhao 4379 (SWFC).

Distribution: Asia-China; Europe-Belarus, France, Spain, Ukraine [64].

Corticium roseocarneum (Schwein.) Hjortstam, Windahlia 23: 2 (1998).

Specimens examined: on the trunk of angiosperm, 6 October 2017, CLZhao 4719; on the fallen branch of angiosperm, 6 October 2017, CLZhao 4545, CLZhao 4735; 7 January 2019, CLZhao 9815; on the trunk of Pinus, 2 October 2017, CLZhao 3562 (SWFC).

Distribution: Asia-China, Japan; Europe—France, Norway; North America — Canada [64].

Crustodontia chrysocreas (Berk. and M.A. Curtis) Hjortstam and Ryvarden, Syn. Fung. (Oslo) 20: 36 (2005).

Specimens examined: on the fallen branch of angiosperm, 5 October 2017, CLZhao 4143; 7 January 2019, CLZhao 9831 (SWFC).

Distribution: Asia-China; Europe-Belarus, France [64].

Dacryobolus angiospermarum S.H. He, in Xu, Liu, Wu and He, Phytotaxa 365(2): 190 (2018). Specimens examined: on the fallen branch of Pinus, 3 October 2017, CLZhao 3706 (SWFC).

Distribution: Asia-China [64].

Daedaleopsis confragosa (Bolton) J. Schröt., in Cohn, Krypt.-Fl. Schlesien (Breslau) 3.1(25-32): 492 (1888).

Specimens examined: on the trunk of angiosperm, 5 October 2017, CLZhao 4260; on the stump of angiosperm, 10 January 2019, CLZhao 10379, CLZhao 10,447 (SWFC).

Distribution: Africa-Nigeria, South Africa; Asia-China, Azerbaijan, Bhutan, India, Iran, Japan, Malaysia, Nepal, North Korea; Europe-Andorra, Austria, Belgium, Bulgaria, Croatia, Czech Republic, Denmark, Estonia, Finland, France, Germany, Hungary, Ireland, Italy, Latvia, Lithuania, Luxembourg, Netherlands, Norway, Poland, Romania, Russia, Serbia, Slovakia, Slovenia, Spain, Sweden, Switzerland, the United Kingdom, Ukraine; North America-Canada, Mexico, the United States; South America-Brazil, Venezuela; Oceania-Australia [64].

Datronia mollis (Sommerf.) Donk, Persoonia 4(3): 338 (1966).

Specimens examined: on dead tree of angiosperm, 6 October 2017, CLZhao 4429; on the trunk of angiosperm, 4 January 2019, CLZhao 9326 (SWFC).

Distribution: Asia-China; Europe-Russia; North America-the United States [64].

Datronia stereoides (Fr.) Ryvarden, Blyttia 25: 168 (1967).

Specimens examined: on the fallen branch of angiosperm, 7 January 2019, CLZhao 9937 (SWFC).

Distribution: Asia-China, Japan, Kyrgyzstan, North Korea; Europe-Austria, Finland, France, Hungary, Norway, Russia, Spain, Sweden, Switzerland, the United Kingdom; North America-Canada, Costa Rica, Honduras, Mexico, the United States; South America-Brazil, Colombia, Guyana, Paraguay, Venezuela; Oceania-Australia [64].

Earliella scabrosa (Pers.) Gilb. and Ryvarden, Mycotaxon 22(2): 364 (1985).

Specimens examined: on the trunk of angiosperm, 3 October 2017, CLZhao 3688, CLZhao 3701, CLZhao 3722, CLZhao 3754, CLZhao 3766; on the stump of angiosperm, 3 October 2017, CLZhao 3730 (SWFC).

Distribution: Asia-China, India, Malaysia, Philippines, Sri Lanka; North America-the United States [64].

Fibroporia albicans B.K. Cui and Yuan Y. Chen, in Chen, Li and Cui, Phytotaxa 203(1): 51 (2015). 
Specimens examined: on the trunk of angiosperm, 6 October 2017, CLZhao 4416 (SWFC).

Distribution: Asia-China [64].

Flavodon ambrosius D.R. Simmons, You Li, C.C. Bateman and J. Hulcr, Mycotaxon 131(2): 279 (2016).

Specimens examined: on the trunk of angiosperm, 1 October 2017, CLZhao 3341 (SWFC).

Distribution: Asia-China; North America—the United States [64].

Fomes fomentarius (L.) Fr., Summa veg. Scand., Sectio Post. (Stockholm): 321 (1849).

Specimens examined: on the trunk of angiosperm, 6 October 2017, CLZhao 4393 (SWFC).

Distribution: Asia-China, Japan; Europe-Austria, Belgium, Czech Republic, Denmark, Estonia, Finland, France, Germany, Italy, Luxembourg, Netherlands, Norway, Poland, Russia, Slovenia, Spain, Sweden, the United Kingdom, Ukraine; North America-Canada, the United States [64]. Ganoderma australe (Fr.) Pat., Bull. Soc. mycol. Fr. 5(2,3): 65 (1889) (Figure 3).
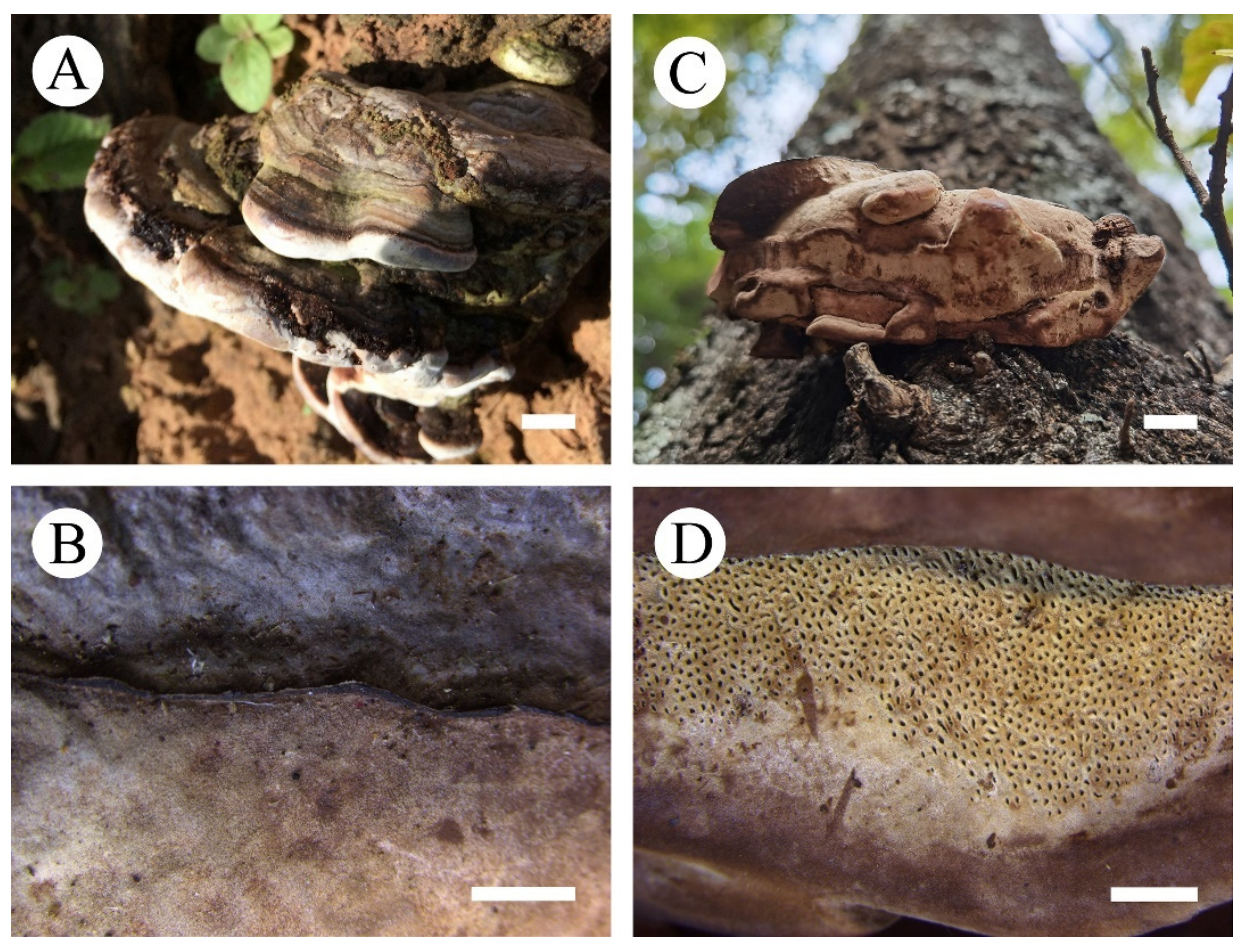

Figure 3. Basidiomata in situ of Ganoderma australe. (A,B) The front of the basidiomata; (C) the back of the basidiomata; (D) a section of hymenophore. Bars: $(\mathbf{A})=(\mathbf{C})=1 \mathrm{~cm} ;(\mathbf{B})=(\mathbf{D})=2 \mathrm{~mm}$.

Specimens examined: on the trunk of angiosperm, 5 October 2017, CLZhao 4351 (SWFC).

Distribution: Asia-China; Europe-France, the United Kingdom; North AmericaCanada, the United States; Oceania-Australia, New Zealand [64].

Gloeodontia yunnanensis C.L. Zhao, in Chen, Shi, Wu and Zhao, Phytotaxa 432(2): 115 (2020).

Specimens examined: on angiosperm trunk, 10 January 2019, CLZhao 10,504 (SWFC).

Distribution: Asia-China [64].

Gloeophyllum sepiarium (Wulfen) P. Karst. (as ‘Gleophyllum'), Bidr. Känn. Finl. Nat. Folk 37: 79 (1882) (Figure 4). 

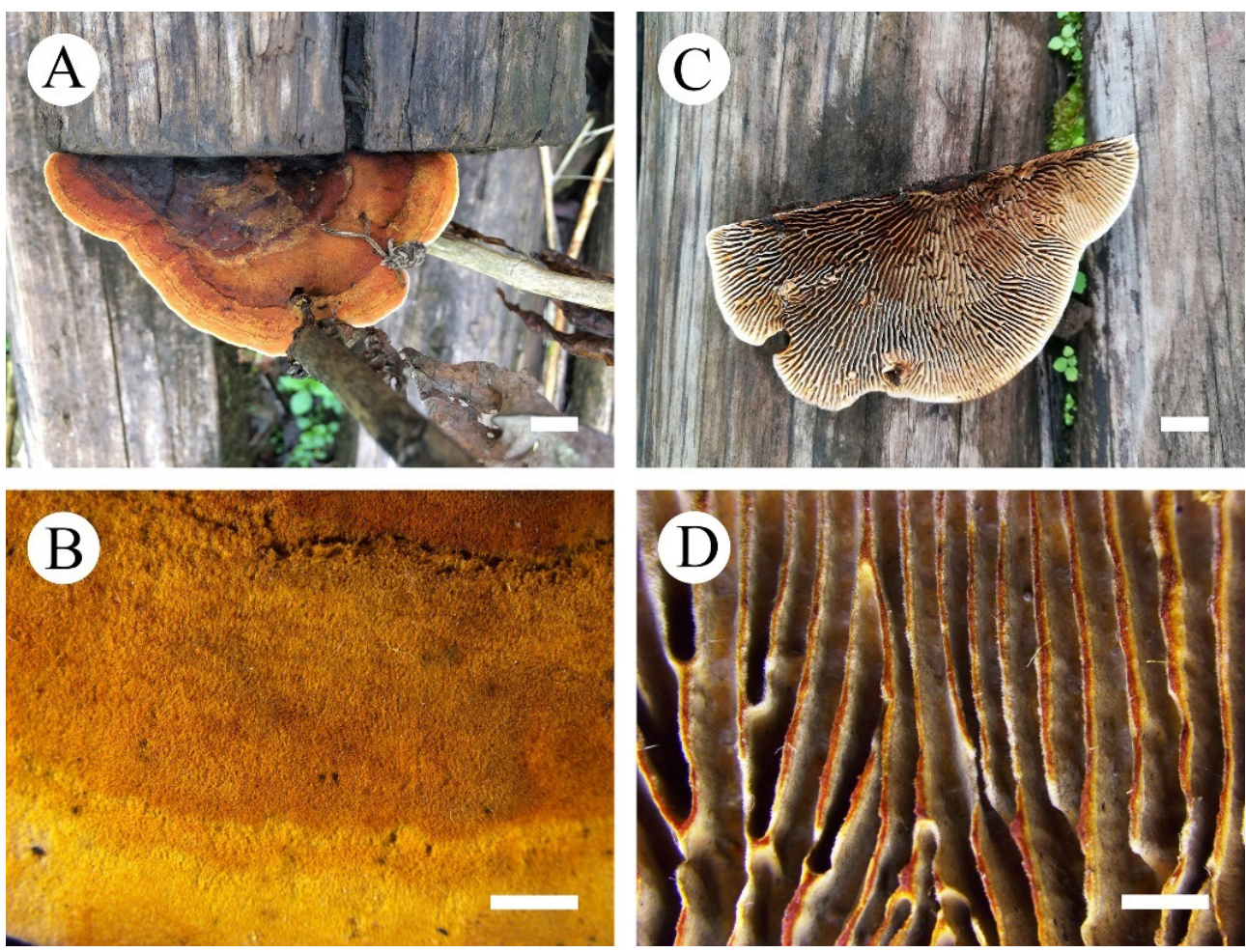

Figure 4. Basidiomata in situ of Gloeophyllum sepiarium. (A,B) The front of the basidiomata; (C) the back of the basidiomata; (D) a section of hymenophore. Bars: $(A)=(\mathbf{C})=1 \mathrm{~cm} ;(\mathbf{B})=(\mathbf{D})=2 \mathrm{~mm}$.

Specimens examined: on the trunk of angiosperm, 2 October 2017, CLZhao 3473, CLZhao 3500, CLZhao 3555, CLZhao 3559, CLZhao 3575; 5 October 2017, CLZhao 4155; 6 October 2017, CLZhao 4532; on the fallen branch of Pinus, 3 October 2017, CLZhao 3680 (SWFC).

Distribution: Asia-China, Japan; Europe-Russia; North America-the United States [64].

Gyrodontium sacchari (Spreng.) Hjortstam, Mycotaxon 54: 186 (1995).

Specimens examined: on the stump of angiosperm, 3 October 2017, CLZhao 3572 (SWFC).

Distribution: Asia—China, India; Europe-Belgium, Italy, Sweden; North AmericaMexico [64].

Heterobasidion insulare (Murrill) Ryvarden (as 'insularis'), Norw. Jl Bot. 19: 237 (1972) (Figure 5). 

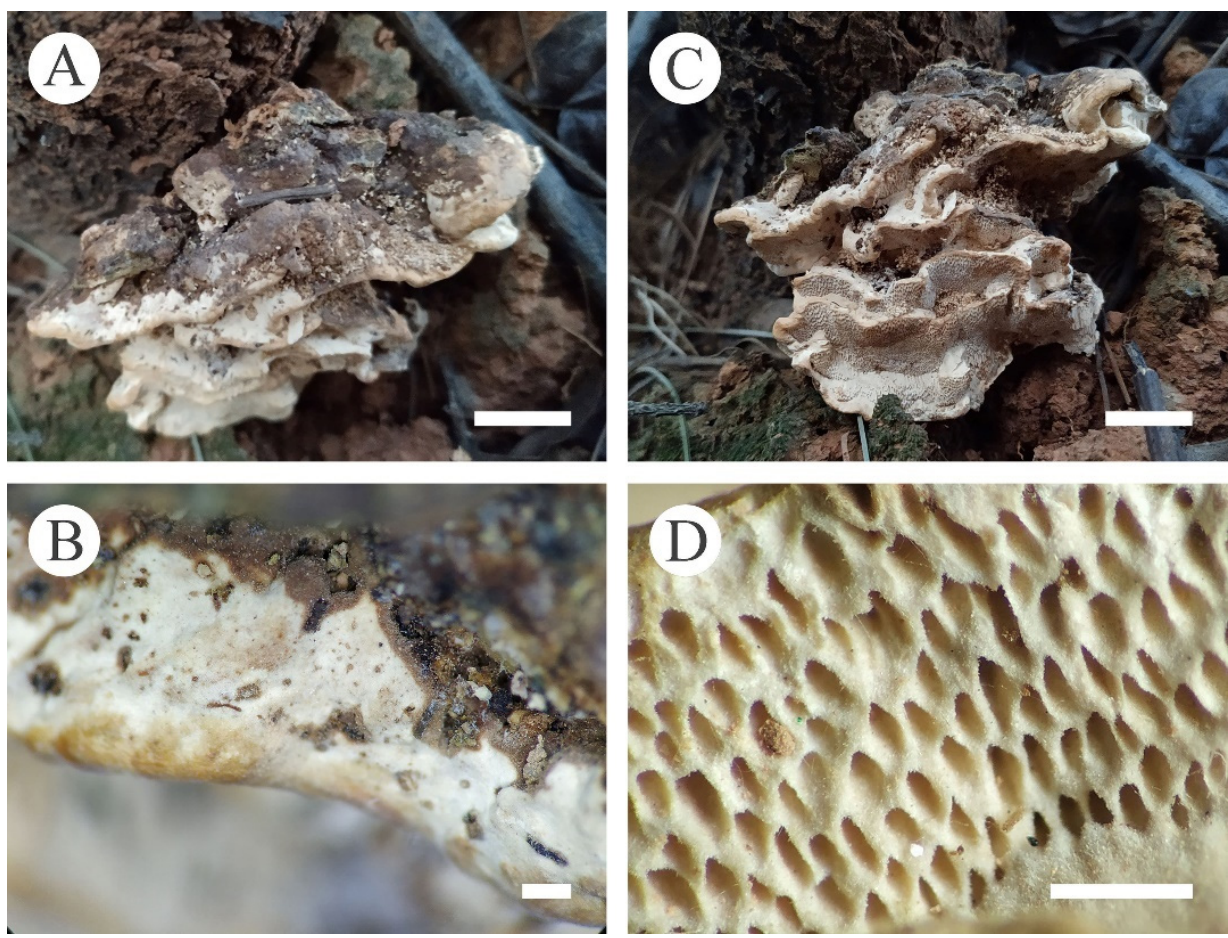

Figure 5. Basidiomata in situ of Heterobasidion insulare. (A,B) The front of the basidiomata; (C) the back of the basidiomata; (D) a section of hymenophore. Bars: $(A)=(\mathbf{C})=1 \mathrm{~cm} ;(\mathbf{B})=(\mathbf{D})=1 \mathrm{~mm}$.

Specimens examined: on the trunk of angiosperm, 5 October 2017, CLZhao 4071, CLZhao 4132, CLZhao 4145, CLZhao 4220, CLZhao 4363; on the stump of angiosperm, 5 October 2017, CLZhao 4224; on the trunk of Pinus, 5 October 2017, CLZhao 4216 (SWFC).

Distribution: Asia-China, India, Japan, Korea, Myanmar, Nepal, South Korea; Europe-Russia [64].

Hexagonia glabra (P. Beauv.) Ryvarden (as 'glaber'), Mycotaxon 72: 216 (1999).

Specimens examined: on the fallen branch of angiosperm, 2 October 2017, CLZhao 3589 (SWFC).

Distribution: Africa-Tanzania, Mauritius; Asia—China, India, Japan, Philippines, Thailand, Vietnam; North America—Costa Rica; South America-Brazil; Oceania-Australia [64].

Hexagonia tenuis (Fr.) Fr., Epicr. syst. mycol. (Upsaliae): 498 (1838).

Specimens examined: on the trunk of angiosperm, 2 October 2017, CLZhao 3485, CLZhao 3498 (SWFC).

Distribution: Asia—China, India, Japan, Malaysia, Philippines, Sri Lanka. Oceania— Australia [64].

Hydnoporia corrugata (Fr.) K.H. Larss. and Spirin, in Miettinen, Larsson and Spirin, Fungal Systematics and Evolution 4: 88 (2019).

Specimens examined: on the fallen branch of angiosperm, 7 January 2019, CLZhao 9913; 9 January 2019, CLZhao 10170, CLZhao 10207; 10 January 2019, CLZhao 10344, CLZhao 10,362 (SWFC).

Distribution: Asia—China, Japan, Sri Lanka; Europe—Denmark, France, Germany, Ireland, Netherlands, Norway, Russia, Spain, Sweden, Switzerland, the United Kingdom, Yugoslavia; North America-Canada, the United States; South America-Argentina, Colombia; Oceania-New Zealand [64].

Hymenochaete berteroi Pat., Bull. Soc. mycol. Fr. 10(2): 78 (1894).

Specimens examined: on the fallen branch of angiosperm, 5 October 2017, CLZhao 4203, CLZhao 4328 (SWFC).

Distribution: Africa—Kenya, Malawi, Tanzania; Asia—China; North America-Costa Rica; South America-Venezuela [64]. 
Hymenochaete innexa G. Cunn., Trans. Roy. Soc. N.Z. 85(1): 47 (1957).

Specimens examined: on the fallen branch of angiosperm, 6 October 2017, CLZhao 4433, CLZhao 4458, CLZhao 4584, CLZhao 4586, CLZhao 4731; 3 January 2019, CLZhao 9255; 5 January 2019, CLZhao 9528 (SWFC).

Distribution: Africa-Seychelles; Asia-China, India; North America-Jamaica, the United States; South America-Brazil; Oceania-Australia, New Zealand [64].

Hyphoderma moniliforme (P.H.B. Talbot) Manjón, G. Moreno and Hjortstam, in Hjortstam, Manjón and Moreno, Mycotaxon 33: 261 (1988).

Specimens examined: on the fallen branch of angiosperm, 9 January 2019, CLZhao 10176, CLZhao 10232, CLZhao 10242; 10 January 2019, CLZhao 10,386 (SWFC).

Distribution: Asia-China; Europe-Spain [64].

Hyphoderma mutatum (Peck) Donk, Fungus, Wageningen 27: 15 (1957).

Specimens examined: on the fallen branch of angiosperm, 9 January 2019, CLZhao 10019, CLZhao 10050, CLZhao 10104, CLZhao 10139, CLZhao 10141, CLZhao 10,203 (SWFC).

Distribution: Asia-China, Japan; Europe-Denmark, Finland, Norway, Sweden; North America-Canada, the United States [64].

Hyphoderma nudicephalum Gilb. And M. Blackw., Mycotaxon 33: 378 (1988).

Specimens examined: on the trunk of angiosperm, 2 October 2017, CLZhao 3481 (SWFC).

Distribution: Asia-China, Japan, Korea; Europe-Denmark, Spain; Oceania-Australia, New Zealand [64].

Hyphoderma transiens (Bres.) Parmasto, Consp. System. Corticiac. (Tartu): 114 (1968) Specimens examined: on the fallen branch of angiosperm, 6 January 2019, CLZhao 9628 (SWFC).

Distribution: Asia-China, Japan [64].

Irpex lacteus (Fr.) Fr., Elench. fung. (Greifswald) 1: 142 (1828) (Figure 6).
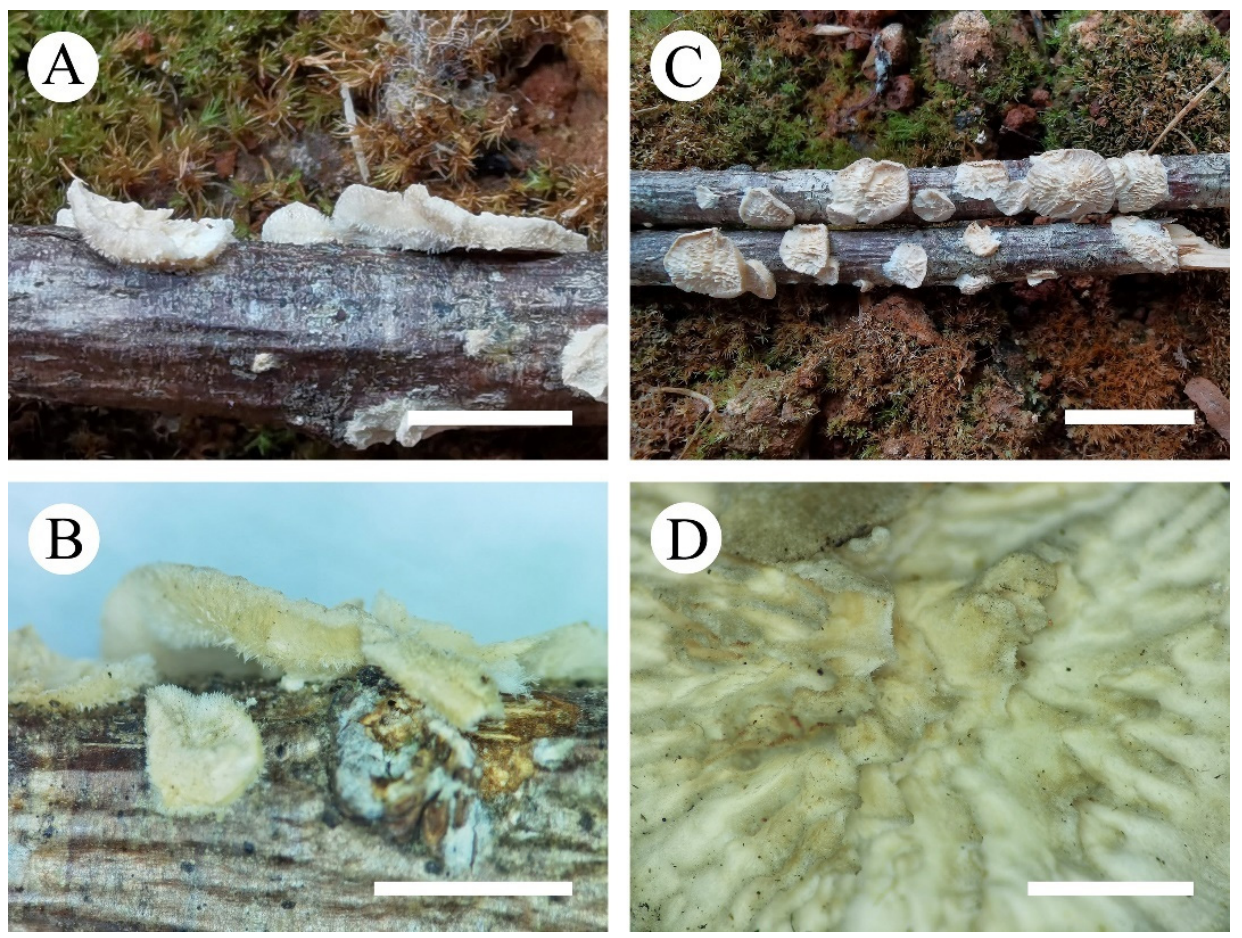

Figure 6. Basidiomata in situ of Irpex lacteus. (A,B) The front of the basidiomata; (C) the back of the basidiomata; (D) a section of hymenophore. Bars: $(\mathbf{A})=(\mathbf{C})=1 \mathrm{~cm} ;(\mathbf{B})=(\mathbf{D})=1 \mathrm{~mm}$.

Specimens examined: on the trunk of angiosperm, 5 October 2017, CLZhao 4338, CLZhao 4365; 6 October 2017, CLZhao 4579; 4 January 2019, CLZhao 9438; 6 January 2019, CLZhao 9765; 7 January 2019, CLZhao 9816, CLZhao 9824, CLZhao 9855, CLZhao 9883, CLZhao 9922; on the fallen branch of angiosperm, 6 October 2017, CLZhao 4609, CLZhao 
4730, CLZhao 9398, CLZhao 9612, CLZhao 9728, CLZhao 9748; 7 January 2019, CLZhao 9878, CLZhao 9888, CLZhao 10,113 (SWFC).

Distribution: Asia-China, Japan; Europe-France, the United Kingdom; North Americathe United States [64].

Junghuhnia crustacea (Jungh.) Ryvarden, Persoonia 7(1): 18 (1972).

Specimens examined: on the fallen branch of angiosperm, 2 October 2017, CLZhao 3588 (SWFC).

Distribution: Asia-China; North America—the United States; South America-Brazil [64].

Junghuhnia nitida (Pers.) Ryvarden, Persoonia 7(1): 18 (1972).

Specimens examined: on the trunk of angiosperm, 2 October 2017, CLZhao 3650; 6 October 2017, CLZhao 4439, CLZhao 4455, CLZhao 4631; on the fallen branch of angiosperm, 2 October 2017, CLZhao 3474, CLZhao 3480; 5 October 2017, CLZhao 4219; 6 October 2017, CLZhao 4702; 5 January 2019, CLZhao 9447, CLZhao 9588; 6 January 2019, CLZhao 9667, CLZhao 9707; 7 January 2019, CLZhao 9854, CLZhao 9884, CLZhao 9919, CLZhao 9943, CLZhao 9969, CLZhao 9998; 9 January 2019, CLZhao 10082, CLZhao 10097, CLZhao 10178, CLZhao 10186, CLZhao 10211, CLZhao 10252, CLZhao 10271, CLZhao 10323; 10 January 2019, CLZhao 10350, CLZhao 10436, CLZhao 10458, CLZhao 10476, CLZhao 10497, CLZhao 10,535 (SWFC).

Distribution: Asia-China, Japan; Europe-France, the United Kingdom; North America-the United States [64].

Laxitextum incrustatum Hjortstam and Ryvarden, Mycotaxon 13(1): 35 (1981).

Specimens examined: on the trunk of angiosperm, 4 January 2019, CLZhao 9273 (SWFC).

Distribution: Africa-Tanzania, Ethiopia; Asia-China; North America-the United States; South America-Brazil [64].

Lenzites betulinus (L.) Fr. (as 'betulina'), Epicr. syst. mycol. (Upsaliae): 405 (1838).

Specimens examined: on the trunk of angiosperm, 5 October 2017, CLZhao 4268, CLZhao 4281; 9 January 2019, CLZhao 10151; on the stump of angiosperm, 10 January 2019, CLZhao 10425, CLZhao 10454, CLZhao 10498, CLZhao 10,516 (SWFC).

Distribution: Asia-China, Japan, North Korea, Philippines; Europe-Austria, Belgium, Denmark, Estonia, Finland, France, Germany, Netherlands, Norway, Russia, Slovenia, Spain, Sweden, the United Kingdom; North America-Canada, Mexico, the United States; South America-Brazil [64].

Lopharia ayresii (Berk. ex Cooke) Hjortstam, Mycotaxon 54: 188 (1995).

Specimens examined: on the trunk of angiosperm, 9 January 2019, CLZhao 10074, CLZhao 10,103 (SWFC).

Distribution: Africa-Angola, Eswatini, Kenya, Mauritius, South Africa, Tanzania, Uganda, Zimbabwe; Asia-China, Sri Lanka; North America-the United States; South America-Brazil, Ecuador; Oceania-Australia [64].

Lopharia mirabilis (Berk. and Broome) Pat., Bull. Soc. mycol. Fr. 11(1): 14 (1895).

Specimens examined: on the trunk of angiosperm, 2 October 2017, CLZhao 3518, CLZhao 3519, CLZhao 3670; 6 October 2017, CLZhao 4399, CLZhao 4620; on the fallen branch of angiosperm, 4 January 2019, CLZhao 9376 (SWFC).

Distribution: Africa-Congo; Asia-China, India, Japan, Sri Lanka, Thailand; EuropeRussia [64].

Lyomyces bambusinus C.L. Zhao, in Chen and Zhao, MycoKeys 65: 105 (2020).

Specimens examined: on dead bamboo, 3 October 2017, CLZhao 3675; 11 January 2018, CLZhao 4808, CLZhao 4831, CLZhao 4840 (SWFC).

Distribution: Asia-China [64].

Lyomyces cremeus C.L. Zhao, in Chen and Zhao, MycoKeys 65: 108 (2020).

Specimens examined: on fallen branch of angiosperm, 21 August 2017, CLZhao 2812, CLZhao 4138; 23 August 2018, CLZhao 8295 (SWFC).

Distribution: Asia-China [64].

Lyomyces macrosporus C.L. Zhao, in Chen and Zhao, MycoKeys 65: 108 (2020). 
Specimens examined: on the fallen branch of angiosperm, 6 October 2017, CLZhao 4516, CLZhao 4531 (SWFC).

Distribution: Asia-China [64].

Lyomyces wuliangshanensis C.L. Zhao, in Chen and Zhao, MycoKeys 65: 111 (2020).

Specimens examined: on the trunk of angiosperm, 5 October 2017, CLZhao 4108, CLZhao 4144, CLZhao 4167; on fallen branch of angiosperm, 6 October 2017, CLZhao 4475; on the stump of angiosperm, 5 October 2017, CLZhao 4206 (SWFC).

Distribution: Asia-China [64].

Megasporia ellipsoidea (B.K. Cui and P. Du) B.K. Cui and Hai J. Li, in Li and Cui, Mycologia 105(2): 375 (2013).

Specimens examined: on the fallen branch of angiosperm, 10 January 2019, CLZhao 10,360 (SWFC).

Distribution: Asia-China [64]

Megasporia major (G.Y. Zheng and Z.S. Bi) B.K. Cui and Hai J. Li, in Li and Cui, Mycologia 105(2): 375 (2013).

Specimens examined: on the fallen branch of angiosperm, 10 January 2019, CLZhao 10,363 (SWFC).

Distribution: Asia-China [64].

Megasporoporiella pseudocavernulosa B.K. Cui and Hai J. Li, in Li and Cui, Mycologia 105(2): 378 (2013).

Specimens examined: on the fallen branch of angiosperm, 4 January 2019, CLZhao 9339; 6 January 2019, CLZhao 9593, CLZhao 9688, CLZhao 9750; 7 January 2019, CLZhao 9806; 9 January 2019, CLZhao 10196, CLZhao 10,308 (SWFC).

Distribution: Asia-China [64].

Megasporoporiella subcavernulosa B.K. Cui and Hai J. Li, in Li and Cui, Mycologia 105(2): 378 (2013).

Specimens examined: on the fallen branch of angiosperm, 6 October 2017, CLZhao 4442, CLZhao 4714 (SWFC).

Distribution: Asia-China [64].

Metuloidea murashkinskyi (Burt) Miettinen and Spirin, in Miettinen and Ryvarden, Ann. bot. fenn. 53(3-4): 165 (2016).

Specimens examined: on the trunk of angiosperm, 3 October 2017, CLZhao 3669, CLZhao 4454; on the fallen branch of angiosperm, 5 January 2019, CLZhao 9455 (SWFC).

Distribution: Asia-China, Japan; Europe-Bulgaria, Iran, Russia [64].

Microporus vernicipes (Berk.) Kuntze, Revis. gen. pl. (Leipzig) 3(3): 497 (1898).

Specimens examined: on the trunk of angiosperm, 5 October 2017, CLZhao 4311, CLZhao 4361; 6 October 2017, CLZhao 4419; on the fallen branch of angiosperm, 2 October 2017, CLZhao 3672 (SWFC).

Distribution: Africa-Kenya, Zambia; Asia—China, Japan, Vietnam [64].

Microporus xanthopus (Fr.) Kuntze, Revis. gen. pl. (Leipzig) 3(3): 494 (1898).

Specimens examined: on the trunk of angiosperm, 5 October 2017, CLZhao 4280; 5 January 2019, CLZhao 9577; on the fallen branch of angiosperm, 1 October 2017, CLZhao 3419 (SWFC).

Distribution: Asia-China, Japan, Malaysia [64].

Neodatronia sinensis B.K. Cui, Hai J. Li and Y.C. Dai, in Li, Cui and Dai, Persoonia 32: 178 (2014).

Specimens examined: on the fallen branch of angiosperm, 5 January 2019, CLZhao 9471 (SWFC).

Distribution: Asia-China [64].

Nigroporus vinosus (Berk.) Murrill, Bull. Torrey bot. Club 32(7): 361 (1905).

Specimens examined: on the trunk of angiosperm, 1 October 2017, CLZhao 3393; on the fallen branch of angiosperm, 1 October 2017, CLZhao 3376 (SWFC). 
Distribution: Africa-Mozambique, Niger, Syria; Asia-China, Japan, Saudi Arabia; Europe-Spain; North America-Cuba, Mexico, Panama, the United States; OceaniaAustralia [64].

Oxychaete cervinogilva (Jungh.) Miettinen, in Miettinen, Spirin, Vlasák, Rivoire, Stenroos and Hibbett, MycoKeys 17: 20 (2016).

Specimens examined: on the trunk of angiosperm, 2 October 2017, CLZhao 3462, CLZhao 3465, CLZhao 3482, CLZhao 3642, CLZhao 3657, CLZhao 3663 (SWFC).

Distribution: Asia-China; Oceania-Australia [64].

Peniophora cinerea (Pers.) Cooke, Grevillea 8 (no. 45): 20 (1879).

Specimens examined: on the fallen branch of angiosperm, 3 January 2019, CLZhao 9254 (SWFC).

Distribution: Asia-China, India, Japan, Turkey; Europe-Austria, Denmark, Estonia, Finland, France, Germany, Italy, Netherlands, Norway, Poland, Portugal, Russia, Sweden, Ukraine; North America-Canada, Cuba, Jamaica, Mexico, the United States; South America-Brazil; Oceania-Australia, New Zealand [64].

Peniophora incarnata (Pers.) P. Karst., Hedwigia 28: 27 (1889) (Figure 7).
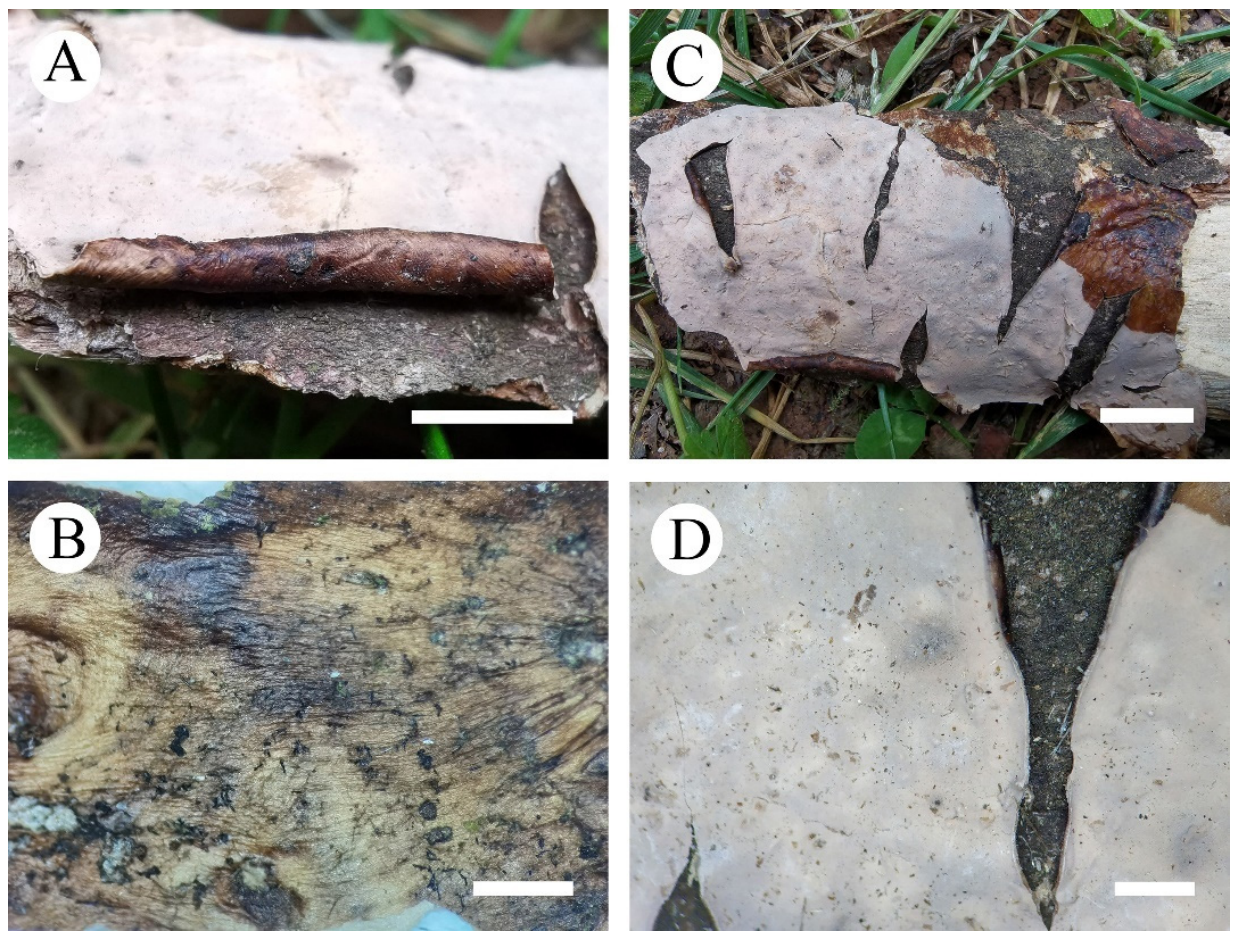

Figure 7. Basidiomata in situ of Peniophora incarnata. (A,B) The front of the basidiomata; (C) the back of the basidiomata; (D) a section of hymenophore. Bars: $(\mathbf{A})=(\mathbf{C})=1 \mathrm{~cm} ;(\mathbf{B})=(\mathbf{D})=2 \mathrm{~mm}$.

Specimens examined: on the trunk of angiosperm, 7 January 2019, CLZhao 9859 (SWFC).

Distribution: Africa-Morocco; Asia-China, India, Iran, Japan; Europe-Austria, Belgium, Czech Republic, Denmark, Finland, France, Germany, Iceland, Ireland, Italy, Netherlands, Norway, Poland, Portugal, Russia, Sweden, Switzerland, the United Kingdom, Ukraine; North America-Canada, Mexico, the United States; South America-Brazil, Chile; Oceania-Australia, New Zealand [64].

Peniophora pseudoversicolor Boidin, Bull. mens. Soc. linn. Lyon 34: 162 (1965).

Specimens examined: on the fallen branch of angiosperm, 4 January 2019, CLZhao 9415 (SWFC).

Distribution: Asia-China, Turkmenistan; Europe-Belgium, Denmark, Estonia, France, Germany, Italy, Portugal, Spain; Oceania-Australia [64].

Peniophorella fissurata C.L. Zhao, in Guan, Zhao and Zhao, Mycol. Progr. 19(4): 400 (2020). 
Specimens examined: on the fallen branch of angiosperm, 6 October 2017, CLZhao 4539; 4 January 2019, CLZhao 9421 (SWFC).

Distribution: Asia-China [64].

Peniophorella pubera (Fr.) P. Karst., Bidr. Känn. Finl. Nat. Folk 48: 427 (1889).

Specimens examined: on the fallen branch of angiosperm, 4 January 2019, CLZhao 9336, CLZhao 9405 (SWFC).

Distribution: Asia-China, Japan; Europe-Denmark, Finland, Norway, Sweden, North America-Canada, the United States [64].

Peniophorella rude (Bres.) K.H. Larss., Mycol. Res. 111(2): 192 (2007).

Specimens examined: on the fallen branch of angiosperm, 1 October 2017, CLZhao 3360; 5 October 2017, CLZhao 4086, CLZhao 4300; 7 January 2019, CLZhao 9862; 9 January 2019, CLZhao 10212; 10 January 2019, CLZhao 10,419 (SWFC).

Distribution: Asia-China, Japan; North America—the United States; South AmericaBrazil [64].

Perenniporia luteola B.K. Cui and C.L. Zhao, in Zhao and Cui, Mycoscience 54(3): 235 (2013).

Specimens examined: on the dead tree of angiosperm, 10 January 2019, CLZhao 10354; on the trunk of angiosperm, 10 January 2019, CLZhao 10334, CLZhao 10345, CLZhao 10403, CLZhao 10406, CLZhao 10411; on the fallen branch of angiosperm, 10 January 2019, CLZhao 10353, CLZhao 10355, CLZhao 10376, CLZhao 10384, CLZhao 10,393 (SWFC).

Distribution: Asia-China [64].

Perenniporia mopanshanensis C.L. Zhao, in Zhao and Ma, Mycotaxon 134(1): 132 (2019).

Specimens examined: on the trunk of angiosperm, 6 October 2017, CLZhao 4677, CLZhao 4693; on the fallen branch of angiosperm, 6 October 2017, CLZhao 4708 (SWFC).

Distribution: Asia-China [64].

Phaeophlebiopsis peniophoroides (Gilb. and Adask.) Floudas and Hibbett, Fungal Biology 119(7): 710 (2015).

Specimens examined: on the trunk of angiosperm, 2 October 2017, CLZhao 3637 (SWFC).

Distribution: Asia-China; North America-the United States; South AmericaBrazil [64]. $166(2000)$

Phanerochaete angustocystidiata Sheng H. Wu, Bot. Bull. Acad. sin., Taipei 41(2):

Specimens examined: on the fallen branch of angiosperm, 4 January 2019, CLZhao 9280, CLZhao 9505 (SWFC).

Distribution: Asia-China [64].

Phanerochaete australis Jülich, in Jermy, J. Linn. Soc., Bot. 81(1): 43 (1980).

Specimens examined: on the stump of angiosperm, 2 October 2017, CLZhao 3571 (SWFC).

Distribution: Asia-China, Indonesia, Malaysia [64].

Phanerochaete concrescens Spirin and Volobuev, in Volobuev, Okun, Ordynets and Spirin, Mycol. Progr. 14(no. 80): 7 (2015).

Specimens examined: on the trunk of angiosperm, 5 October 2017, CLZhao 4367; 5 January 2019, CLZhao 9585; 7 January 2019, CLZhao 9856, CLZhao 9899 (SWFC).

Distribution: Asia-China; Europe-Russia [64].

Phanerochaete sanguineocarnosa Floudas and Hibbett, Fungal Biology 119(7): 688 (2015).

Specimens examined: on the trunk of angiosperm, 6 September 2017, CLZhao 4447, CLZhao 4639, CLZhao 4691 (SWFC).

Distribution: Asia-China; North America-the United States [64].

Phanerochaete sordida (P. Karst.) J. Erikss. and Ryvarden, in Eriksson, Hjortstam and Ryvarden, Cortic. N. Eur., 5 (Oslo): 1023 (1978).

Specimens examined: on the trunk of angiosperm, 5 October 2017, CLZhao 4238, CLZhao 4270; 9 January 2019, CLZhao 10290; 10 January 2019, CLZhao 10347; on the fallen branch of angiosperm, 1 October 2017, CLZhao 3407; 5 October 2017, CLZhao 4082, CLZhao 4084, CLZhao 4091; 5 January 2019, CLZhao 9460; 7 January 2019, CLZhao 9936, CLZhao 9983; 9 January 2019, CLZhao 10172, CLZhao 10213, CLZhao 10314; 10 January 2019, CLZhao 10337, CLZhao 10366, CLZhao 10378, CLZhao 10390, CLZhao 10392, CLZhao 
10402, CLZhao 10413, CLZhao 10439, CLZhao 10466, CLZhao 10518; on the fallen branch of Pinus, 5 October 2017, CLZhao 4087, CLZhao 4094, CLZhao 4134, CLZhao 4140, CLZhao 4187, CLZhao 4360 (SWFC).

Distribution: Asia-China, Iran, Japan, Nepal, Thailand; Europe-Denmark, Finland, Sweden; North America-Canada, the United States; Oceania-Australia [64].

Phlebiopsis castanea (Lloyd) Miettinen and Spirin, in Miettinen, Spirin, Vlasák, Rivoire, Stenroos and Hibbett, MycoKeys 17: 25 (2016).

Specimens examined: on the fallen branch of angiosperm, 2 October 2017, CLZhao 3501 (SWFC).

Distribution: Asia-China, Japan, South Korea, Thailand; Europe-Russia [64].

Phlebiopsis crassa (Lév.) Floudas and Hibbett, Fungal Biology 119(7): 710 (2015) (Figure 8).
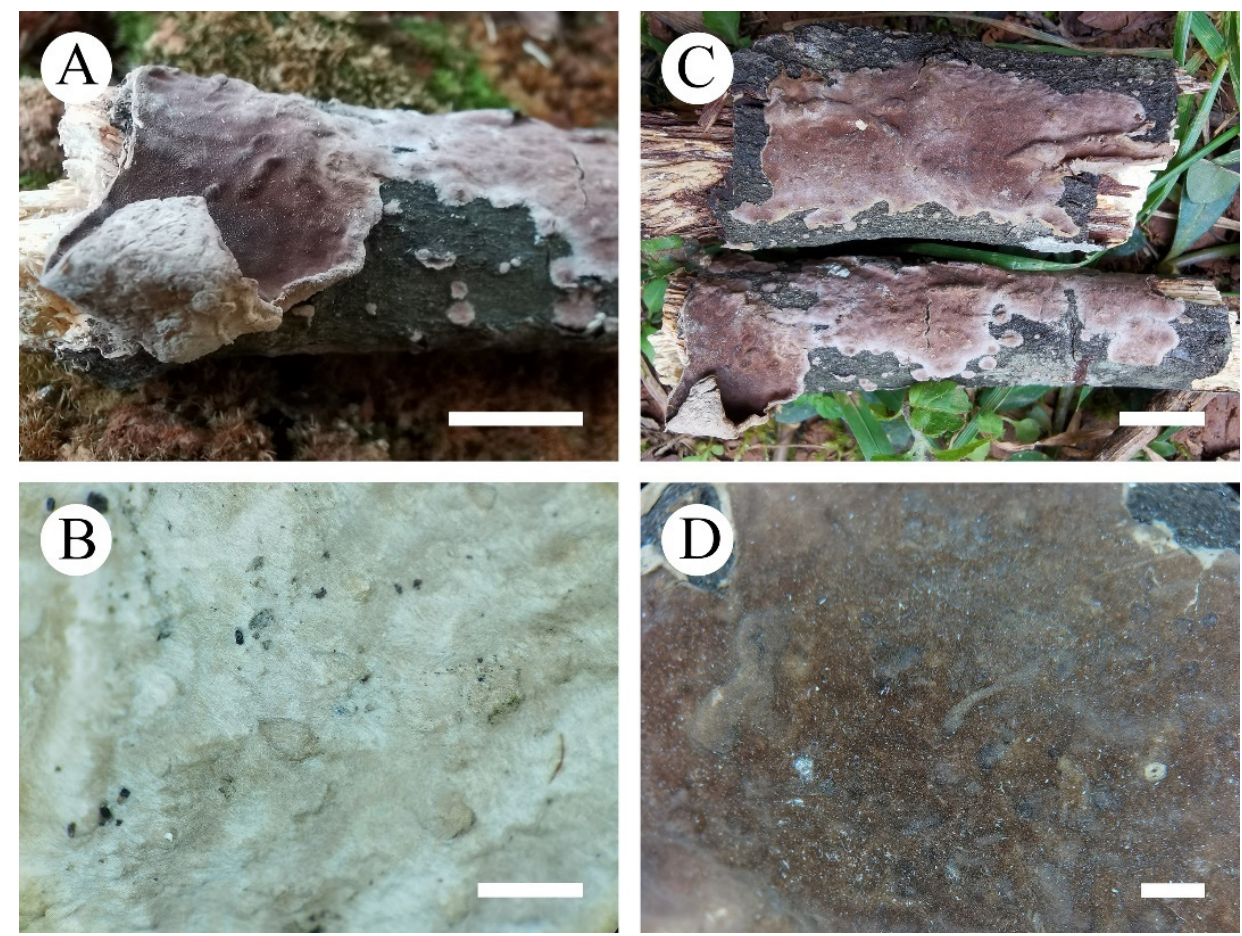

Figure 8. Basidiomata in situ of Phlebiopsis crassa. (A,B) The front of the basidiomata; (C) the back of the basidiomata; (D) a section of hymenophore. Bars: $(\mathbf{A})=(\mathbf{C})=1 \mathrm{~cm} ;(\mathbf{B})=1 \mathrm{~mm} ;(\mathbf{D})=2 \mathrm{~mm}$.

Specimens examined: on the trunk of angiosperm, 5 October 2017, CLZhao 4128; 7 January 2019, CLZhao 9817; on the fallen branch of angiosperm, 1 October 2017, CLZhao 3339, 5 October 2017, CLZhao 4123, CLZhao 4172, CLZhao 4194, CLZhao 4225; 6 October 2017, CLZhao 4640; 4 January 2019, CLZhao 9316; 5 January 2019, CLZhao 9458, CLZhao 9539; 7 January 2019, CLZhao 9801, CLZhao 9827, CLZhao 9838 (SWFC).

Distribution: Asia-China, Vietnam; Europe-Belgium; North America-the United States; Oceania-Australia [64].

Pycnoporus sanguineus (L.) Murrill, Bull. Torrey bot. Club 31(8): 421 (1904).

Specimens examined: on the trunk of angiosperm, 5 October 2017, CLZhao 4129, CLZhao 4234 (SWFC).

Distribution: Asia-China; Europe-France; North America-the United States; Oceania-Australia [64].

Rhomboidia wuliangshanensis C.L. Zhao, in $\mathrm{Xu}$, Liu, Chen and Zhao, Mycotaxon 134(4): 656 (2020).

Specimens examined: on the trunk of angiosperm, 6 October 2017, CLZhao 4406, CLZhao 4411 (SWFC).

Distribution: Asia-China [64]. 
Rigidoporus pouzarii Vampola and Vlasák, Czech Mycol. 64(1): 5 (2012).

Specimens examined: on the trunk of angiosperm, 6 October 2017, CLZhao 4524 (SWFC).

Distribution: Asia-China; Europe-Germany, Ukraine; North America-the United States [64].

Serpula dendrocalami C.L. Zhao, in Wang, Das, Bera, Chen, Bhatt, Ghosh, Hembrom, Hofstetter, Parihar, Vizzini, Xu, Zhao and Buyck, Cryptog. Mycol. 40(5): 88 (2019).

Specimens examined: on the dead bamboo, 2 October 2017, CLZhao 3521, CLZhao 3607, CLZhao 3626, CLZhao 3632 (SWFC).

Distribution: Asia-China [64].

Sistotrema brinkmannii (Bres.) J. Erikss., K. Fysiogr. Sällsk. Lund. Förhandl. 18 (no. 8): 134 (1948).

Specimens examined: on the trunk of angiosperm, 4 January 2019, CLZhao 9324, CLZhao 9344, CLZhao 9347 (SWFC).

Distribution: Asia-China; Europe-Bulgaria, Denmark, France, Germany, Italy, Poland, Portugal, Romania, Russia, Spain, the United Kingdom; North America-the United States; South America-Brazil [64].

Sistotremastrum guttuliferum Melo, M. Dueñas, Tellería and M.P. Martín, in Telleria, Melo, Dueñas, Salcedo, Beltrán-Tejera, Rodríguez-Armas and Martín, Mycol. Progr. 12(3): 688 (2012).

Specimens examined: on the trunk of angiosperm, 6 January 2019, CLZhao 9771; on the fallen branch of angiosperm, 5 January 2019, CLZhao 9454 (SWFC).

Distribution: Asia-China, South Korea; Europe-Romania, Spain [64].

Steccherinum bourdotii Saliba and A. David, Cryptog. Mycol. 9(2): 100 (1988).

Specimens examined: on the stump of angiosperm, 13 January 2018, CLZhao 4297; 10 January 2019, CLZhao 10,340 (SWFC).

Distribution: Asia-China, India; Europe-Belgium, Czech Republic, France, Germany, Russia, Switzerland [64].

Steccherinum confragosum Maas Geest. and Lanq., Persoonia 8(2): 149 (1975).

Specimens examined: on the fallen branch of angiosperm, 5 October 2017, CLZhao 4347 (SWFC).

Distribution: Asia-China; Europe-Belarus, France [64].

Steccherinum ochraceum (Pers. ex J.F. Gmel.) Gray, Nat. Arr. Brit. Pl. (London) 1: 651 (1821).

Specimens examined: on the trunk of angiosperm, 6 October 2017, CLZhao 4523; 4 January 2019, CLZhao 9290; on the fallen branch of angiosperm, 7 January 2019, CLZhao 9953; 9 January 2019, CLZhao 10,055 (SWFC).

Distribution: Asia-China, Japan; Europe-Denmark, Germany, Norway, Spain, Sweden; North America-the United States; Oceania-Australia [64].

Terana coerulea (Lam.) Kuntze, Revis. gen. pl. (Leipzig) 2: 872 (1891).

Specimens examined: on the fallen branch of angiosperm, 6 January 2019, CLZhao 9613; 7 January 2019, CLZhao 9803, CLZhao 9812 (SWFC).

Distribution: Asia-China, Turkey; Europe-Belgium, Croatia, Czech Republic, Denmark, France, Germany, Greece, Italy, Macedonia, Portugal, Slovenia, Spain, Sweden, Switzerland, the United Kingdom, Ukraine [64].

Tinctoporellus epimiltinus (Berk. and Broome) Ryvarden, Trans. Br. mycol. Soc. 73(1): 18 (1979).

Specimens examined: on the trunk of angiosperm, 2 October 2017, CLZhao 3605 (SWFC).

Distribution: Asia-China, Japan, Malaysia; Europe-the United Kingdom; North America-Mexico [64].

Trametes ellipsospora Ryvarden, Mycotaxon 28(2): 539 (1987).

Specimens examined: on the fallen branch of angiosperm, 3 October 2017, CLZhao 3774 (SWFC).

Distribution: Asia-China; North America-the United States [64].

Trametes hirsuta (Wulfen) Lloyd, Mycol. Writ. (Cincinnati) 7(Letter 73): 1319 (1924) 
Specimens examined: on the trunk of angiosperm, 5 October 2017, CLZhao 4278, CLZhao 4279, CLZhao 4342; on the fallen branch of angiosperm, 5 October 2017, CLZhao 4070, CLZhao 4170; 7 January 2019, CLZhao 9912, CLZhao 9986; on the stump of angiosperm, 2 October 2017, CLZhao 3572; on the fallen branch of Pinus, 5 October 2017, CLZhao 4295 (SWFC).

Distribution: Asia-China, India; Europe-Poland, the United Kingdom [64].

Trametes pavonia (Berk.) Fr., Nova Acta R. Soc. Scient. upsal., Ser. 3 1(1): 98 (1851).

Specimens examined: on the fallen branch of angiosperm, 2 October 2017, CLZhao 3740 (SWFC).

Distribution: Asia-China; North America-the United States; South AmericaArgentina, Brazil [64].

Trametes versicolor (L.) Lloyd, Mycol. Notes (Cincinnati) 65: 1045 (1921) (Figure 9).
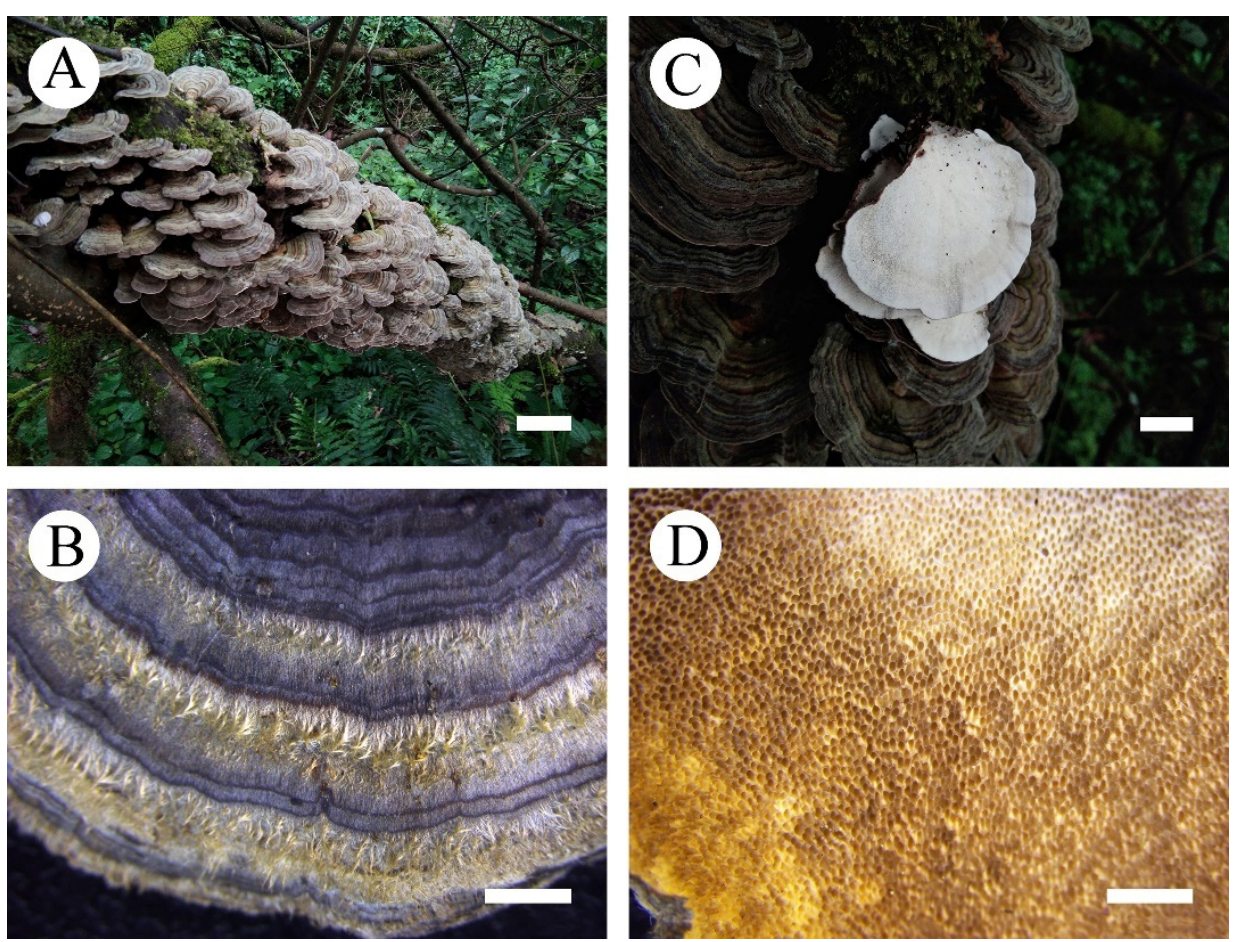

Figure 9. Basidiomata in situ of Trametes versicolor. (A,B) The front of the basidiomata; (C) the back of the basidiomata; (D) a section of hymenophore. Bars: $(A)=4 \mathrm{~cm} ;(\mathbf{B})=(\mathbf{D})=2 \mathrm{~mm} ;(\mathbf{C})=1 \mathrm{~cm}$.

Specimens examined: on the trunk of angiosperm, 6 October 2017, CLZhao 4451, CLZhao 4497, CLZhao 4627; 5 January 2019, CLZhao 9587; 9 January 2019, CLZhao 10090; on the fallen branch of angiosperm, 6 October 2017, CLZhao 4487 (SWFC).

Distribution: Asia-China, India, Japan; Europe-Belgium, Denmark, Finland, France, Germany, Greece, Italy, Norway, Poland, Portugal, Spain, Sweden, the United Kingdom; North America-the United States [64].

Trametopsis cervina (Schwein.) Tomšovský, Czech Mycol. 60(1): 7 (2008).

Specimens examined: on the fallen branch of angiosperm, 5 January 2019, CLZhao 9449, CLZhao 9493 (SWFC).

Distribution: Africa-Morocco; Asia-China, India; Europe-Germany, the United Kingdom [64].

Trechispora nivea (Pers.) K.H. Larss., Symb. bot. upsal. 30(no. 3): 110 (1995).

Specimens examined: on the trunk of angiosperm, 9 January 2019, CLZhao 10154, CLZhao 10297; 10 January 2019, CLZhao 10373, CLZhao10389, CLZhao 10398, CLZhao 10,442 (SWFC). 
Distribution: Asia-China; Europe-Austria, Belgium, Czech Republic, Denmark, Estonia, Finland, France, Germany, Italy, Norway, Poland, Romania, Russia, Spain, Sweden, Switzerland, the United Kingdom [64].

Truncospora ochroleuca (Berk.) Pilát, Sb. Nár. Mus. v Praze, Rada B, Prír. Vedy 9(2): 108 (1953).

Specimens examined: on the trunk of angiosperm, 5 October 2017, CLZhao 4350; on the stump of angiosperm, 4 January 2019, CLZhao 9328 (SWFC).

Distribution: Africa-Ethiopia, Kenya, Malawi, Tanzania; Asia-China, India, Japan, Malaysia, Singapore, Sri Lanka, Vietnam; Europe-Finland, France, Russia; North AmericaMexico, the United States; South America-Brazil; Oceania-Australia, New Zealand [64].

\section{Discussion}

Both phyla Ascomycota and Basidiomycota cover around 97\% of all fungal species in the kingdom fungi [65]. On the basis of the latest version of Ainsworth and Bisby's Dictionary of the Fungi [66], 1589 genera and more than 30 thousand species of Basidiomycota were included, and many taxa were recorded all over the world every year, which observably increase the fungal diversity [7,67-74]. The wood-decaying fungi have been extensively studied in China [6,7,68,72,73,75-78], but the diversity of wood-decaying fungi in the Wuliangshan area is yet elusive. The present paper is the first report of a series of studies devoted to wood-decaying fungi in this area and contributes to reveal abundance of wood-decaying species. A total of 2454 specimens belonging to 95 wood-decaying poroid and corticioid species were collected from the Wuliangshan area and identified based on morphological studies and phylogenetic analysis. According to the previous studies $[6,16,63]$ combined with field observations, five species (5.26\% of the total), Dacryobolus angiospermarum, Fibroporia albicans, Gloeophyllum sepiarium, Hymenochaete berteroi, and Serpula dendrocalami can cause a brown rot; the remaining 90 species $(94.74 \%$ of the total) cause a white rot. In contrast, the proportion of brown-rot fungus in the Wuliangshan area is similar to that in the Haikou Forestry Farm which is 6.12\% [78], but lower than Huangshan Mountains, Laojun Mountains and Great Xingan Mountains at 14.12\%, 25\% and $26.19 \%$, respectively [75-77].

Although some remarkable explorations of wood-decaying fungi have been made from the Yunnan Province [57,68,79-89], only nine new species, Rhomboidia wuliangshanensis, Gloeodontia yunnanensis, Lyomyces bambusinus, L. cremeus, L. macrosporus, L. wuliangshanensis, Peniophorella fissurata, Perenniporia mopanshanensis and Serpula dendrocalami were found from the Wuliangshan area $[85,86,90-93]$. Species in the present list are mostly new to the studied area. All collected specimens were confirmed to be 95 species, which are distributed in 59 genera, 23 families, and 9 orders (Table 2). Of these 95 species listed, 67 species belong to the order Polyporales, accounting for $70.53 \%$, indicating that polypores are the dominant group in this area; 12 species belong to the order Russulales; 6 species belong to the Hymenochaetales; 3 species belong to the Auriculariales; 2 species belong to Boletales and Trechisporales, and 1 species belongs to Cantharellales, Corticiales and Gloeophyllales. The present study indicates that Aleurodiscus botryosus, A. cerussatus, A. mirabilis, Asterostroma muscicola, Auricularia cornea, A. delicata, Bjerkandera adusta, Byssomerulius corium, Daedaleopsis confragosa, Datronia stereoides, Fomes fomentarius, Hydnoporia corrugata, Lenzites betulinus, Lopharia ayresii, Nigroporus vinosus, Peniophora cinerea, P. incarnata, Sistotrema brinkmannii, Steccherinum ochraceum, Terana coerulea, Trametes versicolor, Trechispora nivea and Truncospora ochroleuca species are common, Abundisporus quercicola, Aleurodiscus isabellinus, Gloeodontia yunnanensis, Lyomyces bambusinus, L. cremeus, L. macrosporus, L. wuliangshanensis, Megasporoporiella pseudocavernulosa, Peniophorella fissurata, Perenniporia luteola, P. mopanshanensis, Phanerochaete angustocystidiata, Rhomboidia wuliangshanensis and Serpula dendrocalami are rare worldwide according to the distribution, whereas 69 species belong to rare native species (fewer than five specimens followed previous study [6]); 49 species are distributed in Eurasia, and 61 are spread in the Northern Hemisphere; Bjerkandera adusta and Fomes fomentarius could function as indicators that detect heavy metal biosorption; Bjerkandera adusta, 
Daedaleopsis confragosa, Datronia stereoides, Fomes fomentarius and Peniophora incarnata are expansive, and Cerrena albocinnamomea, Heterobasidion insulare, Phanerochaete concrescens and Phlebiopsis castanea are invasive in the Wuliangshan area. In addition, the underlying fungal diversity in the Wuliangshan area is unpredictable, and a more intensive investigation is needed to complement the further biodiversity.

Table 2. Number of wood-inhabiting poroid and corticioid species in the most representative orders, families, and genera in the study area and proportion accounting for total species number.

\begin{tabular}{|c|c|c|c|c|c|c|c|c|c|c|c|}
\hline Orders & & & & & Families & & & & Genera & & \\
\hline Order & Family & Genera & Spp. & $\%$ & Family & Genera & Spp. & $\%$ & Genera & Spp. & $\%$ \\
\hline Polyporales & 9 & 40 & 67 & 70.53 & Polyporaceae & 18 & 28 & 29.47 & Aleurodiscus & 5 & 5.26 \\
\hline Russulales & 5 & 6 & 12 & 12.63 & Phanerochaetaceae & 6 & 11 & 11.58 & Phanerochaete & 5 & 5.26 \\
\hline Hymenochaetales & 2 & 3 & 6 & 6.32 & Steccherinaceae & 5 & 8 & 8.42 & Hyphoderma, & 4 & 4.21 \\
\hline Auriculariales & 1 & 1 & 3 & 3.16 & Hyphodermataceae & 2 & 8 & 8.42 & Lyomyces & 4 & 4.21 \\
\hline Boletales & 2 & 4 & 2 & 2.11 & Stereaceae & 2 & 6 & 6.32 & Trametes & 4 & 4.21 \\
\hline Trechisporales & 1 & 2 & 2 & 2.11 & Irpicaceae & 5 & 5 & 5.26 & Auricularia & 3 & 3.16 \\
\hline Cantharellales & 1 & 1 & 1 & 1.05 & Cerrenaceae & 2 & 3 & 3.16 & Peniophora & 3 & 3.16 \\
\hline Corticiales & 1 & 1 & 1 & 1.05 & Hymenochaetaceae & 2 & 3 & 3.16 & Peniophorella & 3 & 3.16 \\
\hline \multirow[t]{3}{*}{ Gloeophyllales } & 1 & 1 & 1 & 1.05 & Rickenellaceae & 1 & 3 & 3.16 & Steccherinum & 3 & 3.16 \\
\hline & & & & & Subtotal & 43 & 75 & 78.95 & Subtotal & 34 & 35.79 \\
\hline & & & & & $\begin{array}{l}\text { Other families } \\
\qquad(14)\end{array}$ & 16 & 20 & 21.05 & $\begin{array}{l}\text { Other } \\
\text { genera } \\
(50)\end{array}$ & 61 & 64.21 \\
\hline Total & 23 & 59 & 95 & $100 \%$ & 23 & 59 & 95 & $100 \%$ & 59 & 95 & $100 \%$ \\
\hline
\end{tabular}

As an essential component of the forest ecosystems, most of the wood-inhabiting poroid and corticioid fungi function as wood decomposers that release matter and energy to the ecological system [94-96]. Herein, we further found 2 edible fungi, Auricularia cornea and A. delicata, according to Dai et al. [97], together with 14 medicinal fungi, Bjerkandera adusta, Cerrena zonata, Daedaleopsis confragosa, Earliella scabrosa, Fomes fomentarius, Ganoderma australe, Gloeophyllum sepiarium, Hexagonia tenuis, Irpex lacteus, Lenzites betulinus, Lopharia ayresii, Pycnoporus sanguineus, Trametes hirsuta and T. versicolor, according to Dai and Yang [98]. Some notable medical fungi were found, such as Bjerkandera adusta, a potential antineoplastic agent [99], as well as Trametes hirsute, which possesses the effect of curing rheumatism and relieving cough [100,101]. In addition, an industrial white-rot fungus was also found in this study. As a target of interest, Trametes versicolor was conducted under a free or immobilized laccase condition exploring its biocatalytic characterization in the activation zone [102]. Moreover, though these saprophytic species possess powerful enzymes, which can effectively degrade lignocellulose [103], Abundisporus quercicola, Bjerkandera adusta, Ceriporia lacerata, Cerrena zonata, C. albocinnamomea, Daedaleopsis confragosa, Fomes fomentarius and Gyrodontium sacchari are treated as forest pathogens contrarily [104].

Phylogenetically, based on a study of the molecular systematics on the subphyla Agaricomycotina, Pucciniomycotina and Ustilaginomycotina with combined nLSU, SSU, $5.8 \mathrm{~s}, \mathrm{rpb} 1, \mathrm{rpb} 2$, and tef1 datasets, He et al. [105] revealed 1928 currently used genera names, which are distributed in 241 families, 68 orders, 18 classes and 4 subphyla. In the present study, 95 species nested in 59 genera, 23 families, and 9 orders based on the ITS dataset, which is similar to the previous studied topology [105], were revealed. Sequences of ITS gene regions of the studied samples were generated, which illustrates that all collected fungal specimens from the Wuliangshan area belonging to Agaricomycetes distribute into Auriculariales, Boletales, Cantharellales, Corticiales, Gloeophyllales, Hymenochaetales, Polyporales, Russulales and Trechisporales (Figure 1). Phylogenetic analyses of all studied samples shows that the individual taxon clusters closely with the downloaded reliable sequence from previous studies with a supported rate (Figure 2).

Based on the early embrace of molecular systematics by mycologists, both the discovery and classification of fungi among the more basal branches of the tree are now coming to light from genomic analyses and environmental DNA surveys [1]. Several 
comprehensively remarkable collections of wood-decaying fungi in China have been performed based on the combination of morphological features and molecular evidence; Dai illustrated 80 pathogenic wood-decaying fungi in 2005, which mainly belong to Ganodermataceae, Climacodontaceae, Corticiaceae, Hericiaceae, Hymenochataceae, Polyporaceae, and Schizophyllaceae of Basidiomycota [106]. In addition, Dai reported 140 wood-decaying fungi on stored wood or structural timber in 2009, and 29 are brown-rot and 111 are white-rot fungus [107]. The fungal diversity from the Hainan area in China showed that it includes 240 species, of which 199 are polypores, and 41 are corticoid and other woodinhabiting fungi [108]. In addition, this place is located at the longitude and latitude of $108^{\circ} 37^{\prime}-111^{\circ} 03^{\prime} \mathrm{E}$ and $18^{\circ} 10^{\prime}-20^{\circ} 10^{\prime} \mathrm{N}$. The Atlas of Chinese Macrofungal Resources revealed that it has 1819 species belonging to 509 genera. According to their morphological characteristics, they are divided into 10 groups, including 196 larger Ascomycetes, 21 jelly fungi, 47 coral fungi, 637 polyporoid, hydnaceous and thelephoroid fungi, 11 cantharelloid fungi, 653 agarics, 130 boletes, 75 gasteroid fungi, 16 larger pathogenic fungi on crops, and 33 larger Myxomycetes [109]. The book of Atlas of Macrofungi in Saihanwula National Nature Reserve of Inner Mongolia indicated that it includes 310 species, located in 3 phyla, 8 classes, 24 orders, 66 families, 152 genera [110]; its longitude and latitude are $118^{\circ} 18^{\prime}-118^{\circ} 55^{\prime} \mathrm{E}$ and $43^{\circ} 59^{\prime}-44^{\circ} 27^{\prime} \mathrm{N}$. The result shows that the tropical and subtropical areas have enriched fungal diversity, which supports our research regarding to the richness of wood-decaying fungi in China.

In the last 20 years, dramatic changes in higher-level taxonomy have occurred, as evidenced by a tripling of fungal phyla from 4 to 12 . The hidden and microscopic nature of many fungi also means that their biodiversity is undersampled, in which perhaps less than $5 \%$ of the estimated two to four million species have been formally described $[2,16,111]$. The present work will comprehensively improve the understanding of the diversity of wood-decaying fungi in this area, in which 29 species are new for China, i.e., Aleurodiscus botryosus, Aleurodiscus isabellinus, Auricularia asiatica, Crustodontia chrysocreas, Flavodon ambrosius, Gloeodontia yunnanensis, Hyphoderma moniliforme, Hyphoderma nudicephalum, Hyphoderma transiens, Laxitextum incrustatum, Lyomyces bambusinus, Lyomyces cremeus, Lyomyces macrosporus, Lyomyces wuliangshanensis, Peniophora pseudoversicolor, Peniophorella fissurata, Peniophorella pubera, Peniophorella rude, Perenniporia mopanshanensis, Phaeophlebiopsis peniophoroides, Phanerochaete concrescens, Phanerochaete sanguineocarnosa, Rhomboidia wuliangshanensis, Rigidoporus pouzarii, Serpula dendrocalami, Sistotremastrum guttuliferum, Steccherinum bourdotii, Steccherinum confragosum and Terana coerulea. The research region of woodinhabiting fungi in the Wuliangshan area covers 2,581 square kilometres, accounting for $0.65 \%$ of the area of the Yunnan Province and for $0.027 \%$ of China. This work is conducive to the rational utilization and effective protection of fungal resources, and provides scientific basis for the prevention and control of forest diseases in this area.

Author Contributions: Conceptualization, C.-L.Z.; methodology, C.-L.Z. and X.H.; software, C.-L.Z. and X.H.; validation, C.-L.Z. and X.H.; formal analysis, C.-L.Z. and X.H.; investigation, C.-L.Z. and X.H.; resources, C.-L.Z.; writing—original draft preparation, C.-L.Z. and X.H.; writing-review and editing, C.-L.Z. and X.H.; visualization, C.-L.Z. and X.H.; supervision, C.-L.Z.; project administration, C.-L.Z.; funding acquisition, C.-L.Z. All authors have read and agreed to the published version of the manuscript.

Funding: The research was supported by the National Natural Science Foundation of China (Project No. 32170004, U2102220), Yunnan Fundamental Research Project (Grant No. 202001AS070043) and High-level Talents Program of Yunnan Province (YNQR-QNRC-2018-111).

Institutional Review Board Statement: Not applicable for studies involving humans or animals.

Informed Consent Statement: Not applicable for studies involving humans. 
Data Availability Statement: Publicly available datasets were analyzed in this study. This data can be found here: https:/ / www.ncbi.nlm.nih.gov/; https:/ / www.mycobank.org/page/Simple\%20nam es\%20search; http:/ / purl.org/phylo/treebase, submission ID 29040; accessed on 23 November 2021.

Conflicts of Interest: The authors declare no conflict of interest.

\section{References}

1. James, T.Y.; Stajich, J.E.; Hittinger, C.T.; Rokas, A. Toward a fully resolved fungal tree of life. Annu. Rev. Microbiol. 2020, 74, 291-313. [CrossRef] [PubMed]

2. Blackwell, M. The Fungi: 1, 2, 3 . . 5.1 million species? Am. J. Bot. 2011, 98, 426-438. [CrossRef] [PubMed]

3. Taylor, D.L.; Hollingsworth, T.N.; Mcfarland, J.W. A first comprehensive census of fung i in soil reveals bothhyperdiversity and fine-scale niche partitioning. Ecol. Monogr. 2014, 84, 3-20. [CrossRef]

4. Hibbett, D. The invisible dimension of fungal diversity. Science 2016, 351, 1150. [CrossRef]

5. Russell, R.; Paterson, M. Ganoderma-A therapeutic fungal biofactory. Phytochemistry 2006, 67, 1985-2001. [CrossRef]

6. Dai, Y.C. Polypore diversity in China with an annotated checklist of Chinese polypores. Mycoscience 2012, 53, 49-80. [CrossRef]

7. Dai, Y.C.; Cui, B.K.; Si, J.; He, S.H.; Hyde, K.D.; Yuan, H.S.; Liu, X.Y.; Zhou, L.W. Dynamics of the worldwide number of fungi with emphasis on fungal diversity in China. Mycol. Prog. 2015, 14, 62. [CrossRef]

8. Vinay, D.S.; Ryan, E.P.; Pawelec, G.; Talib, W.H.; Stagg, J.; Elkord, E.; Lichtor, T.; Decker, W.K.; Whelan, R.L.; Kumara, S.; et al. Immune evasion in cancer: Mechanistic basis and therapeutic strategies. Semin. Cancer Biol. 2015, 35, S185-S198. [CrossRef]

9. M'Barek, H.N.; Arif, S.; Taidi, B.; Hajjaj, H. Consolidated bioethanol production from olive mill waste: Wood-decay fungi from central Morocco as promising decomposition and fermentation biocatalysts. Biotechnol. Rep. 2020, 28, e00541. [CrossRef]

10. Runnel, K.; Miettinen, O.; Lohmus, A. Polypore fungi as a flagship group to indicate changes in biodiversity-A test case from Estonia. IMA Fungus 2021, 12, 2. [CrossRef]

11. Yu, Q.G. Wuliangshan National Nature Reserve; Yunnan Science and Technology Press: Kunming, China, 2004; pp. 103-105, 118, 197.

12. Lu, S.Z.; Yu, Q.G.; Cao, S.W. Measurement of ecosystem diversity in Wuliangshan National Nature Reserve and its adjacent area in Yunnan Province. J. Anhui Agric. Sci. 2008, 36, 2426-2428, 2435.

13. Luo, Z.H.; Xie, Y.N.; Luo, Y.; Li, X.Y.; Lu, C.R. Population Characteristics of Tsuga dumosa in Wuliangshan National Nature Reserve. J. West China For. Sci. 2013, 42, 94-99.

14. Gao, L.L.; Yang, H.J.; Liu, G.Z.; Wang, C.H.; Yang, G.P.; Cai, C.T. Diversity of medicinal vascular plant resources in Wuliangshan National Nature Reserve, Yunnan, China. Plant Sci. J. 2018, 36, 203-210.

15. Peng, H.; Wu, Z.Y. The Preliminary Floristical study on mid-montane humid evergreen broad-leaved forest in Mt. Wuliangshan. Acta Bot. Yunnanica 1998, 20, 12-22.

16. Dai, Y.C.; Yang, Z.L.; Cui, B.K.; Wu, G.; Yuan, H.S.; Zhou, L.W.; He, S.H.; Ge, Z.W.; Wu, F.; Wei, Y.L.; et al. Diversity and systematics of the important macrofungi in Chinese forests. Mycosystema 2021, 40, 770-805. [CrossRef]

17. Petersen, J.H. Farvekort. The Danish Mycological Society's Colour-Chart; Foreningen til Svampekundskabens Fremme: Paris, France, 1996; pp. 1-6.

18. White, T.J.; Bruns, T.; Lee, S.; Taylor, J. Amplification and direct sequencing of fungal ribosomal RNA genes for phylogenetics. PCR Protoc. Guide Methods Appl. 1990, 18, 315-322. [CrossRef]

19. Xu, T.M. Study on the Resources and Taxonomy of Wood-Decaying Fungi in Wuliangshan National Nature Reserve, Yunnan Province; Southwest Forestry University: Kunming, China, 2020.

20. Vu, D.; Groenewald, M.; De Vries, M.; Gehrmann, T.; Stielow, B.; Eberhardt, U.; Al-Hatmi, A.; Groenewald, J.Z.; Cardinali, G.; Houbraken, J.; et al. Large-scale generation and analysis of filamentous fungal DNA barcodes boosts coverage for kingdom fungi and reveals thresholds for fungal species and higher taxon delimitation. Stud. Mycol. 2019, 92, 135-154. [CrossRef]

21. Tian, Y.; Ghobad-Nejhad, M.; He, S.H.; Dai, Y.C. Three new species of Aleurodiscus s.l. (Russulales, Basidiomycota) from southern China. MycoKeys 2018, 37, 93-107. [CrossRef]

22. Asl, A.; Syo, A.; Msp, A.; Kim, T.; Yoo, J.S.; Seelan, J.S.S.; Lim, Y.W. Co-occurrence patterns of wood-decaying fungi and ants in dead pines of South Korea-ScienceDirect. J. Asia Pac. Entomol. 2019, 22, 1154-1160. [CrossRef]

23. Bandara, A.R.; Karunarathna, S.C.; Phillips, A.J.L.; Mortimer, P.E.; Xu, J.C.; Kakumyan, P.; Hyde, K.D. Diversity of Auricularia (Auriculariaceae, Auriculariales) in Thailand. Phytotaxa 2017, 292, 19. [CrossRef]

24. Wu, F.; Yuan, Y.; Rivoire, B.; Dai, Y.C. Phylogeny and diversity of the Auricularia mesenterica (Auriculariales, Basidiomycota) complex. Mycol. Prog. 2015, 14, 42. [CrossRef]

25. Floudas, D.; Hibbett, D.S. Revisiting the taxonomy of Phanerochaete (Polyporales, Basidiomycota) using a four gene dataset and extensive ITS sampling. Fungal Biol. 2015, 119, 679-719. [CrossRef]

26. Águeda, B.; Parladé, J.; Fernandez-Toiran, L.M.; Cisneros, Ó.; Miguel, A.M.; Modrego, M.P.; Martínez-Peña, F.; Pera, J. Mycorrhizal synthesis between Boletus edulis species complex and rockroses (Cistus sp.). Mycorrhiza 2008, 18, 443-449. [CrossRef]

27. Deo, G.S.; Khatra, J.; Buttar, S.; Wai, M.L.; Chow, H.L. Anti-proliferative, immuno-stimulatory and anti-inflammatory activities of extracts derived from mushrooms collected in Haida Gwaii, BC (Canada). Int. J. Med. Mushrooms 2019, 21, 629-643. [CrossRef]

28. Shirouzu, T.; Hosaka, K.; Nam, K.O.; Weir, B.S.; Hosoya, T. Phylogenetic relationships of eight new Dacrymycetes collected from New Zealand. Persoonia 2017, 38, 156-169. [CrossRef] 
29. Shirouzu, T.; Hirose, D.; Oberwinkler, F.; Shimomura, N.; Maekawa, N.; Tokumasu, S. Combined molecular and morphological data for improving phylogenetic hypothesis in Dacrymycetes. Mycologia 2013, 105, 1110-1125. [CrossRef]

30. Zamora, J.C.; Ekman, S. Phylogeny and character evolution in the Dacrymycetes, and systematics of Unilacrymaceae and Dacryonaemataceae fam. nov. Persoonia 2020, 44, 161-205. [CrossRef]

31. Chen, Y.Y.; Li, H.J.; Cui, B.K. Molecular phylogeny and taxonomy of Fibroporia (Basidiomycota) in China. Phytotaxa 2015, 203, 47-54. [CrossRef]

32. Li, Y.; Bateman, C.C.; Skelton, J.; Jusino, M.A.; Nolen, Z.J.; Simmons, D.R.; Hulcr, J. Wood decay fungus Flavodon ambrosius (Basidiomycota: Polyporales) is widely farmed by two genera of ambrosia beetles. Fungal Biol. 2017, 121, 984-989. [CrossRef]

33. Jeppson, M.; Nilsson, R.H.; Larsson, E. European earthstars in Geastraceae (Geastrales, Phallomycetidae)—A systematic approach using morphology and molecular sequence data. Syst. Biodivers. 2013, 11, 437-465. [CrossRef]

34. Larsson, K.H. Re-thinking the classification of corticioid fungi. Mycol. Res. 2007, 111, 1040-1063. [CrossRef] [PubMed]

35. Yuan, Y.; Chen, J.J.; Korhonen, K.; Martin, F.; Dai, Y.C. An updated global species diversity and phylogeny in the forest pathogenic genus Heterobasidion (Basidiomycota, Russulales). Front. Microbiol. 2021, 11, 596393. [CrossRef] [PubMed]

36. Ji, X.; Wu, D.M.; Song, C.G.; Liu, S.; Si, J.; Cui, B.K. Two new Neofomitella species (Polyporaceae, Basidiomycota) based on morphological and molecular evidence. Mycol. Prog. 2019, 18, 593-602. [CrossRef]

37. Li, H.J.; Cui, B.K.; Dai, Y.C. Taxonomy and multi-gene phylogeny of Datronia (Polyporales, Basidiomycota). Persoonia 2014, 32, 170-182. [CrossRef]

38. Yurchenko, E.; Wu, S.H. Hyphoderma moniliforme and H. nemorale (Basidiomycota) newly recorded from China. Mycosphere 2015, 6, 113-121. [CrossRef]

39. Larsson, K.H. Molecular phylogeny of Hyphoderma and the reinstatement of Peniophorella. Mycol. Res. 2007, 111, 186-195. [CrossRef]

40. Sulzbacher, M.A.; Grebenc, T.; Nouhra, E.R.; Giachini, A.J.; Martín, M.P.; Baseia, L.G. Hysterangium atlanticum sp. nov. forms ectomycorrhizae with Coccoloba species (Polygonaceae) from the Atlantic rainforest of Northeastern Brazil. Symbiosis 2019, 78 , 275-286. [CrossRef]

41. Miettinen, O.; Larsson, E.; Sjokvist, E.; Larsson, K.H. Comprehensive taxon sampling reveals unaccounted diversity and morphological plasticity in a group of dimitic polypores (Polyporales, Basidiomycota). Cladistics Int. J. Willi Hennig Soc. 2012, 28, 251-270. [CrossRef]

42. Mudalungu, C.M.; Richter, C.; Wittstein, K.; Abdalla, M.A.; Matasyoh, J.C.; Stadler, M.; Süssmuth, R.D. Laxitextines A and B, Cyathane Xylosides from the Tropical Fungus Laxitextum incrustatum. J. Nat. Prod. 2016, 79, 894-898. [CrossRef]

43. Liu, S.L.; Nakasone, K.K.; Wu, S.H.; He, S.H.; Dai, Y.C. Taxonomy and phylogeny of Lopharia s.s Dendrodontia, Dentocorticium and Fuscocerrena (Basidiomycota, Polyporales). MycoKeys 2018, 32, 25-48. [CrossRef]

44. Miettinen, O.; Spirin, V.; Josef, V.; Rivoire, B.; Hibbett, D. Polypores and genus concepts in Phanerochaetaceae (Polyporales, Basidiomycota). MycoKeys 2016, 17, 1-46. [CrossRef]

45. Hallenberg, N.; Nilsson, R.H.; Antonelli, A.; Wu, S.H.; Maekawa, N.; Nordén, B. The Peniophorella praetermissa species complex (Basidiomycota). Mycol. Res. 2008, 111, 1366-1376. [CrossRef]

46. Cabral, T.S.; Silva, B.D.; María, P.M.; Clement, C.R.; Hosaka, K.; Baseia, I.G. Behind the veil—Exploring the diversity in Phallus indusiatus s.l. (Phallomycetidae, Basidiomycota). MycoKeys 2019, 58, 103-127. [CrossRef]

47. Volobuev, S.; Okun, M.; Ordynets, A.; Spirin, V. The Phanerochaete sordida group (Polyporales, Basidiomycota) in temperate Eurasia, with a note on Phanerochaete pallida. Mycol. Prog. 2015, 14, 80. [CrossRef]

48. Melera, S.; Ostellari, C.; Roemer, N.; Avis, P.G.; Tonolla, M.; Barja, F.; Narduzzi-Wicht, B. Analysis of morphological, ecological and molecular characters of Russula pectinatoides Peck and Russula praetervisa Sarnari, with a description of the new taxon Russula recondita Melera \& Ostellari. Mycol. Prog. 2016, 16, 117-134. [CrossRef]

49. Palmer, J.M.; Lindner, D.L.; Volk, T.J. Ectomycorrhizal characterization of an American chestnut (Castanea dentata)-dominated community in Western Wisconsin. Mycorrhiza 2008, 19, 27-36. [CrossRef]

50. Alshammari, N.; Stephenson, S.L. A preliminary study of wood-decay fungi in forests of northwest Arkansas. Curr. Res. Environ. Appl. Mycol. 2018, 8, 556-563. [CrossRef]

51. Justo, A.; Miettinen, O.; Floudas, D.; Ortiz-Santana, B.; Sjökvist, E.; Lindner, D.; Nakasone, K.; Niemelä, T.; Larsson, K.H.; Ryvarden, L.; et al. A revised family-level classification of the Polyporales (Basidiomycota). Fungal Biol. 2017, 121, 798-824. [CrossRef]

52. Zhao, C.L.; Cui, B.K.; Steffen, K.T. Yuchengia, a new polypore genus segregated from Perenniporia (Polyporales) based on morphological and molecular evidence. Nord. J. Bot. 2013, 31, 331-338. [CrossRef]

53. Milenkovic, I.; Tomsovsky, M.; Karadzic, D.; Veselinovic, M. Decline of Paulownia tomentosa caused by Trametes hirsuta in Serbia. For. Pathol. 2018, 48, e12438. [CrossRef]

54. Justo, A.; Hibbett, D.S. Phylogenetic classification of Trametes (Basidiomycota, Polyporales) based on a five-marker dataset. Taxon 2011, 60, 1567-1583. [CrossRef]

55. Telleria, M.T.; Melo, I.; Duenas, M.; Larsson, K.H.; Martín, M.P.P. Molecular analyses confirm Brevicellicium in Trechisporales. IMA Fungus 2013, 4, 21-28. [CrossRef]

56. Hall, T.A. Bioedit: A user-friendly biological sequence alignment editor and analysis program for Windows 95/98/NT. Nucleic Acids Symp. Ser. 1999, 41, 95-98. [CrossRef] 
57. Zhao, C.L.; Wu, Z.Q. Ceriporiopsis kunmingensis sp. nov. (Polyporales, Basidiomycota) evidenced by morphological characters and phylogenetic analysis. Mycol. Prog. 2017, 16, 93-100. [CrossRef]

58. Swofford, D.L. PAUP*: Phylogenetic Analysis Using Parsimony ( ${ }^{*}$ and Other Methods); Version 4.0b10; Sinauer Associates: Sunderland, MA, USA, 2002.

59. Felsenstein, J. Confidence intervals on phylogenetics: An approach using bootstrap. Evolution 1985, 39, 783-791. [CrossRef]

60. Miller, M.A.; Pfeiffer, W.; Schwartz, T. The CIPRES Science Gateway: Enabling High-Impact Science for Phylogenetics Researchers with Limited Resources. Assoc. Comput. Mach. 2012, 39, 1-8. [CrossRef]

61. Nylander, J.A.A. MrModeltest v2. Program Distributed by the Author; Evolutionary Biology Centre, Uppsala University: Uppsala, Sweden, 2004.

62. Ronquist, F.; Huelsenbeck, J.P. MrBayes 3: Bayesian phylogenetic inference under mixed models. Bioinformatics 2003, 19, 1572-1574. [CrossRef]

63. Dai, Y.C. A revised checklist of corticioid and hydnoid fungi in China for 2010. Mycoscience 2011, 52, 69-79. [CrossRef]

64. Zhao, C.L. Wood Inhabiting Fungi Diversity in Wuliangshan Area; China Forestry Publishing House: Beijing, China, 2021.

65. Willis, K.J. State of the World's Fungi 2018; Report; Royal Botanic Gardens: Kew, UK, 2018.

66. Kirk, P.M.; Cannon, P.F.; Minter, D.W.; Stalpers, J.A. Ainsworth E Bisby's Dictionary of the Fungi, 10th ed.; CAB International: Wallingford, UK, 2008.

67. Ayesha, P.; Maham, A.; Ariza, A.; Husnain, H. “Ganoderma lucidum sensu lato"-A sacred mushroom for immortality. Stud. Fungi 2020, 5, 508-516. [CrossRef]

68. Huang, R.X.; Luo, K.Y.; Zhao, C.L. Phlebia nigrodontea sp. nov. in Meruliaceae (Polyporales) with a black hymenial surface. Phytotaxa 2020, 458, 195-206. [CrossRef]

69. Himani, S.; Krishnappa, M. Xylaria oxyacanthae (Xylariaceae), a new record on Diospyros melanoxylon from India. Stud. Fungi 2020, 5, 485-490. [CrossRef]

70. Blanco-Dios, J.B. Notes on the genus Entoloma s.l. in the Northwest of the Iberian Peninsula (XI): A new species in subgenus Entoloma. Stud. Fungi 2021, 6, 64-70. [CrossRef]

71. Kumar, S.; Singh, R. Global diversity and distribution of distoseptosporic micromycete Corynespora Güssow (Corynesporascaceae): An updated checklist with current status. Stud. Fungi 2021, 6, 1-63. [CrossRef]

72. Wang, H.; Zhao, C.L. Hyphodermella aurantiaca sp. nova. (Polyporales, Basidiomycota) as evidenced by morphological characters and phylogenetic analyses. Ann. Bot. Fenn. 2021, 58, 61-68. [CrossRef]

73. Zong, T.K.; Liu, C.M.; Wu, J.R.; Zhao, C.L. Trechispora daweishanensis and T. xantha spp. nov. (Hydnodontaceae, Trechisporales) found in Yunnan Province of China. Phytotaxa 2021, 479, 147-159. [CrossRef]

74. Boonyuen, N.; Chuaseeharonnachai, C.; Nuankaew, S.; Kwantong, P.; Pornputtapong, N.; Suwannarach, N.; Jones, E.B.G.; Somrithipol, S. Novelties in Fuscosporellaceae (Fuscosporellales): Two New Parafuscosporella from Thailand Revealed by Morphology and Phylogenetic Analyses. Diversity 2021, 13, 517. [CrossRef]

75. Cui, B.K.; Jia, B.S. Wood-rotting fungi in eastern China 7. Polypores from Huangshan Mountain, Anhui Province. Mycosystema 2011, 30, 529-535. [CrossRef]

76. Cui, B.K.; Yu, C.J. Fungal flora and population structure of polypores in the Great Hingan Mountains. Acta Ecol. Sin. 2011, 31, 3700-3709.

77. Cui, B.K.; Dai, Y.C. Wood-decaying fungi in eastern Himalayas 3. Polypores from Laojunshan Mountains, Yunnan Province. Mycosystema 2012, 31, 486-492.

78. He, X.; Chen, J.Z.; Zhao, C.L. Diversity of wood-decaying fungi in Haikou Forestry Farm, Yunnan Province, P.R. China. Stud. Fungi 2021, 6, 365-377. [CrossRef]

79. Yuan, H.S.; Dai, Y.C. Polypores from northern and central Yunnan Province, Southwestern China. Sydowia 2008, 60, 147-159.

80. Wu, Z.Q.; Shen, S.; Luo, K.Y.; Wang, Z.H.; Zhao, C.L. Morphological and molecular identification of a new species of Atraporiella (Polyporales, Basidiomycota) in China. Phytotaxa 2017, 332, 31-40. [CrossRef]

81. Shen, S.; Ma, X.; Xu, T.M.; Zhao, C.L. Phlebia ailaoshanensis sp. nov. (Polyporales, Basidiomycota) evidenced by morphological characters and phylogenetic analyses. Phytotaxa 2018, 373, 184-196. [CrossRef]

82. Wu, Z.Q.; Xu, T.M.; Shen, S.; Liu, X.F.; Luo, K.Y.; Zhoa, C.L. Elaphroporia ailaoshanensis gen. et sp nov in Polyporales (Basidiomycota). MycoKeys 2018, 29, 81-95. [CrossRef]

83. Liu, X.F.; Shen, S.; Zhao, C.L. Morphological and molecular identification of a new species of Eichleriella (Auriculariales, Basidiomycota) in China. Phytotaxa 2019, 404, 245-254. [CrossRef]

84. Luo, K.Y.; Ma, X.; Zhao, C.L. Neofavolus yunnanensis sp. nov. (Polyporales, Basidiomycota) from China: Evidence from morphology and DNA sequence data. Phytotaxa 2019, 408, 109-116. [CrossRef]

85. Xu, T.M.; Liu, X.F.; Chen, Y.H.; Zhao, C.L. Rhomboidia wuliangshanensis gen. et sp. nov. from southwestern China. Mycotaxon 2019, 134, 649-662. [CrossRef]

86. Chen, J.Z.; Zhao, C.L. Morphological and molecular identification of four new resupinate species of Lyomyces (Hymenochaetales) from southern China. MycoKeys 2020, 65, 101-118. [CrossRef]

87. Wang, R.Z.; Yuan, Z.Y.; Han, C.Z.; Zhao, C.L. Morphological and molecular identification of a new species of Cinereomyces (Polyporales, Basidiomycota) in southern China. Phytotaxa 2020, 459, 51-60. [CrossRef]

88. Gu, Z.R.; Zhao, C.L. The hidden wood-decaying fungal diversity: Rhizochaete from east Asia. Diversity 2021, 3, 503. [CrossRef] 
89. Luo, K.Y.; Qu, M.H.; Zhao, C.L. Additions to the knowledge of corticioid Xylodon (Schizoporaceae, Hymenochaetales): Introducing three new Xylodon species from southern China. Diversity 2021, 13, 581. [CrossRef]

90. Wang, X.H.; Das, K.; Bera, I.; Chen, Y.H.; Bhatt, R.P.; Ghosh, A.; Hembrom, M.E.; Hofstetter, V.; Parihar, A.; Vizzini, A.; et al. Fungal Biodiversity Profiles 81-90. Cryptogam. Mycol. 2019, 40, 57-95. [CrossRef]

91. Zhao, C.L.; Ma, X. Perenniporia mopanshanensis sp. nov. from China. Mycotaxon 2019, 134, 125-137. [CrossRef]

92. Chen, L.; Shi, Z.J.; Wu, C.H.; Zhao, C.L. Gloeodontia yunnanensis sp. nov. (Russulales, Basidiomycota) from China, evidenced by morphological characters and phylogenetic analyses. Phytotaxa 2020, 432, 111-118. [CrossRef]

93. Guan, Q.X.; Zhao, T.J.; Zhao, C.L. Morphological characters and phylogenetic analyses reveal two new species of Peniophorella from southern China. Mycol. Prog. 2020, 19, 397-404. [CrossRef]

94. Cui, B.K.; Wei, Y.L.; Dai, Y.C. Polypores from Zijin Mountain, Jiangsu Province. Mycosystema 2006, 25, 9-14.

95. Wei, Y.L. Species diversity, fungal flora and distribution characters of polypores in Changbai Mountains, China. Chin. J. Appl. Ecol. 2011, 22, 2711-2717.

96. Gafforov, Y.; Ordynets, A.; Langer, E.; Yarasheva, M.; de Mello Gugliotta, A.; Schigel, D.; Pecoraro, L.; Zhou, Y.; Cai, L.; Zhou, L.W. Species diversity with comprehensive annotations of wood-inhabiting poroid and corticioid fungi in Uzbekistan. Front. Microbiol. 2020, 11, 598321. [CrossRef]

97. Dai, Y.C.; Zhou, L.W.; Yang, Z.L.; Wen, H.A.; Bau, T.; Li, T.H. A revised checklist of edible fungi in China. Mycosystema 2010, 29, 1-21. [CrossRef]

98. Dai, Y.C.; Yang, Z.L. A revised checklist of medicinal fungi in China. Mycosystema 2008, 27, 801-824. [CrossRef]

99. Mao, X.L. The Economic Fungi in China; Science Press: Beijing, China, 1998.

100. Ying, J.Z.; Mao, X.L.; Ma, Q.M. Atlas of Chinese Medicinal Fungi; Science Press: Beijing, China, 1987.

101. Park, W.H.; Lee, H.D. Illustrated Book of Korean Medicinal Mushrooms. Kyo-Hak Publishing Co., Ltd.: Seoul, Korea, 1999.

102. Saoudi, O.; Ghaouar, N. Biocatalytic characterization of free and immobilized laccase from Trametes versicolor in its activation zone. Biol. Macromolocules 2019, 128, 681-691. [CrossRef]

103. Riley, R.; Salamov, A.A.; Brown, D.W.; Nagy, L.G.; Floudas, D.; Held, B.W.; Levasseur, A.; Lombard, V.; Morin, E.; Otillar, R.; et al. Extensive sampling of basidiomycete genomes demonstrates inadequacy of the white-rot/brown-rot paradigm for wood decay fungi. Proc. Natl. Acad. Sci. USA 2014, 111, 9923-9928. [CrossRef]

104. Dai, Y.C. Pathogenic wood-decaying fungi on woody plants in China. Mycosystema 2012, 31, 493-509. [CrossRef]

105. He, M.Q.; Zhao, R.L.; Hyde, K.D.; Begerow, D.; Kemler, M.; Yurkov, A.; McKenzie, E.H.C.; Raspe, O.; Kakishima, M.; SanchezRamirez, S.; et al. Notes, outline and divergence times of Basidiomycota. Fungal Divers. 2019, 99, 105-367. [CrossRef]

106. Dai, Y.C. Illustrations of Pathogenic Wood-Decaying Fungi in China; Science Press: Beijing, China, 2005.

107. Dai, Y.C. Illustrations of Wood-Decaying Fungi on Stored Wood or Structural Timber in China; Science Press: Beijing, China, 2009.

108. Dai, Y.C.; Cui, B.K. Biodiversity of Wood-Inhabiting Fungi in Hainan; Science Press: Beijing, China, 2010.

109. Li, Y.; Li, T.H.; Yang, Z.L.; Bau, T.; Dai, Y.C. Atlas of Chinese Macrofungal Resources; Central China Farmer's Publishing House: Zhengzhou, China, 2015.

110. Liu, T.Z.; Li, G.L. Atlas of Macrofungi in Saihanwula National Nature Reserve of Inner Mongolia; Inner Mongolia Science and Technology Press: Chifeng, Mongolia, 2019.

111. Hawksworth, D.L.; Lücking, R. Fungal diversity revisited: 2.2 to 3.8 million species. Microbiol Spectr. 2017, 5, 4. [CrossRef] 